Hispania Sacra, LXII

126, julio-diciembre 2010, 407-455, ISSN: 0018-215-X

\title{
EL RITO ROMANO EN LA SEGOVIA MEDIEVAL: CATALOGACIÓN Y ANÁLISIS DE UNOS FRAGMENTOS LITÚRGICOS (SIGLOS XII-XVI)*
}

\author{
POR \\ SANTIAgo Ruiz TORRES \\ Universidad Complutense de Madrid
}

\begin{abstract}
RESUMEN
La Catedral de Segovia y el Convento de San José de la misma ciudad custodian un estimable fondo de 89 fragmentos litúrgico-musicales prácticamente inédito. En este artículo presentamos su catalogación y un análisis de su contenido atendiendo a sus peculiaridades codicológicas, paleográficas y musicales. Asimismo, se determina la procedencia de algunos ejemplares y se señalan las principales claves de la liturgia practicada en la ecclesia segobiensis desde la restauración diocesana de 1120 hasta las disposiciones centralizadoras del Concilio de Trento.
\end{abstract}

PALABRAS ClAVE: Diócesis de Segovia, fragmentos litúrgicos, catálogo, rito romano, codicología, paleografía, monodia.

\section{THE ROMAN RITE IN SEGOVIA DURING THE MIDDLE AGES: CATALOGUE AND ANALYSIS OF LITURGICAL FRAGMENTS $\left(12^{\mathrm{TH}}-16^{\mathrm{TH}}\right.$ CENTURIES)}

\section{ABSTRACT}

Segovia Cathedral and the Convent of San José at the same town preserve a valuable collection of 89 unpublished liturgical fragments. The main aim of this

\footnotetext{
* Quiero agradecer a Bonifacio Bartolomé Herrero, archivero de la Catedral de Segovia, su inestimable ayuda en la localización de los pergaminos catedralicios y transcripción de las notas al margen de tenor documental. Gracias, igualmente, a los profesores de la Universidad Complutense de Madrid, Carmen Julia Gutiérrez González y Arturo Tello Ruiz-Pérez, y al benedictino Juan Pablo Rubio Sadia por sus apreciaciones.
} 
article resides in cataloguing and analyzing its content. The approach proposed here will contribute to a greater understanding and definition of its codicological, paleographic and musical features. It also takes into consideration the historical origin of some fragments. Likewise, the liturgy performed at the ecclesia segobiensis from the restoration of its diocese in 1120 to the assimilation of the Council of Trent is also studied.

KEY WORDS: Segovian diocese, liturgical fragments, catalogue, roman rite, codicology, paleography, plainchant.

Recibido/Received 05-01-2009

Aceptado/Accepted 16-10-2009

Desde que en 1963 José Janini publicara en Estudios Segovianos un inventario de los códices litúrgicos del Archivo de la Catedral de Segovia (A. C. Sg.), ${ }^{1}$ escasas han sido las aportaciones que han profundizado en las fuentes litúrgicas locales. ${ }^{2}$ Aunque Janini dio a conocer 11 manuscritos fragmentarios, ${ }^{3}$ su aproximación a este tipo de fuentes resultó muy superficial. Esta falta de atención hacia los fragmentos litúrgicos en Segovia contrasta, en líneas generales, con la situación observada en otros puntos de la geografía española, donde sí se han acometido investigaciones en torno a sus membra disiecta. ${ }^{4}$ El hecho extraña más aún si se tiene en consideración el destacado papel desempeñado por su obispado entre los siglos XII y XVI, apreciable en diversos acontecimientos históricos como la celeridad mostrada en la construcción de espacios destinados al culto tras la repoblación de su capital en 1088,5 su activa participación en

\section{1.}

${ }^{1}$ José JANINI, «Códices litúrgicos de la catedral de Segovia» Estudios Segovianos 15 (1963) 293-

${ }^{2}$ Caso, por ejemplo, de los trabajos de Hilario SANZ y SANZ, «XXV Exposición de Arte Antiguo. Cantorales o libros de coro» Estudios Segovianos 71-72 (1972) 209-226; Antonio Linage CONDE, «La liturgia de la misa en el sínodo del obispo de Segovia Pedro de Cuéllar. 1325» Anuario de Estudios Medievales 16 (1986) 127-145; o Juan Pablo RUBIO SADIA, «Raíces cluniacenses del breviario de Segovia. El oficio de Todos los Santos» Estudios Segovianos 105 (2005) 455-480.

${ }^{3}$ Véanse nos 2 [fragmento de misal] y 8 [fragmentos de antifonario] en JANINI, Códices litúrgicos... 297-298 y 302. El fragmento de misal aparece también descrito en Idem, Manuscritos litúrgicos de las Bibliotecas de España, vol. 1, $\mathrm{n}^{\circ}$ 310, Burgos, 1977, 261.

${ }^{4}$ Es el caso, por ejemplo, del País Vasco [C. RodRíGuez Suso, La monodia litúrgica en el País Vasco, 3 vols., Bilbao, 1993], Cataluña [J. GARRIGOSA I MASSANA, Els manuscrits musicals a Catalunya fins al segle XIII, Lleida, 2003] o Astorga [Carmen Julia GutiÉRreZ GonZÁlez y Francisco Javier LARA LARA, «Fragmentos de música medieval en Astorga. Catalogación de fragmentos y hojas de guarda de manuscritos litúrgico-musicales del archivo diocesano» Archivos Leoneses 91-92 (1992) 399-423]. Destacable es también la reciente publicación a cargo de Susana ZAPKE (ed.), Hispania Vetus: manuscritos litúrgico-musicales de los orígenes visigóticos a la transición francorromana (siglos IX-XII), Bilbao, 2007.

${ }^{5}$ Más de treinta templos, entre parroquiales y conventuales, han sido censados en la capital segoviana a lo largo del siglo XII; María de la Soterraña MARTín Postigo, «Alfonso I el Batallador y Sego-

Hispania Sacra, LXII

126, julio-diciembre 2010, 407-455, ISSN: 0018-215-X 
la colonización de numerosos territorios al sur del Sistema Central, ${ }^{6}$ o la impronta cultural de algunos de sus prelados como Pedro de Cuéllar (1324-1350) o Juan Arias Dávila (1461-1497). ${ }^{7}$

En el Archivo capitular hemos localizado 83 fragmentos litúrgico-musicales, y en el convento de San José, perteneciente a la Orden de las Carmelitas descalzas, se han hallado 6 ítems de estas características. ${ }^{8}$ Todos los manuscritos están fechados entre los siglos XII y XVI, arco cronológico comprendido entre la restauración de la sede episcopal segoviana (1120) y la unificación litúrgica decretada a raíz del Concilio de Trento. Aunque sería deseable ampliar el radio de investigación, incluyendo otros archivos y bibliotecas que pudieran albergar fuentes fragmentarias locales, ${ }^{9}$ consideramos que las muestras examinadas, por calidad y cantidad, resultan suficientemente representativas para apuntar las claves fundamentales del culto litúrgico medieval en la ecclesia segobiensis.

via» Estudios Segovianos $56-57$ (1967) 243; cifra bastante meritoria a tenor de la situación de marginalidad y despoblamiento que atravesó la Extremadura castellana durante la Alta Edad Media. Un dato particularmente significativo que demuestra esta premura en la edificación de espacios sacros es la noticia de la consagración de don Pelayo Mendes como nuevo arzobispo de Braga, celebración acontecida en Segovia el 18 de junio de 1118 con asistencia de la reina Urraca. De este magno acontecimiento y de la convocatoria paralela de una asamblea conciliar, Fita deduce que la ciudad en esa fecha «no estaba destituida de espaciosos templos»; Fidel FITA, «Concilios de Gerona, Segovia y Tuy en 1117 y 1118» Boletín de la Real Academia de la Historia 48 (1906) 509.

${ }^{6}$ L. M. VILlar GARcía, La Extremadura Castellano-Leonesa. Guerreros, clérigos y campesinos (711-1252), Valladolid, 1986, 232-233. Véase también E. ToRMO, «El estrecho cerco del Madrid de la Edad Media por la admirable colonización segoviana»Boletín de la Real Academia de la Historia 118 (1946) 47-206.

7 El primero de ellos destaca por la redacción de un catecismo de corte reformista en el que se compendiaban los principios reguladores de la doctrina cristiana; J. L. Martín y A. LinAgE Conde, $R e$ ligión y sociedad medieval. El catecismo de Pedro de Cuéllar (1325), Valladolid, 1987. El segundo prelado constituye, sin duda, uno de los máximos dinamizadores de Segovia tanto en el plano cultural como en el artístico. Influenciado por las nuevas coordenadas intelectuales impulsadas por el Humanismo, fue el promotor del primer libro impreso en la Península Ibérica: el Sinodal de Aguilafuente (1472).

${ }^{8}$ Dos pergaminos de las religiosas fueron ya descritos por Dámaso García Fraile con motivo de la exposición «Las Edades del Hombre» celebrada en Segovia en 2003; Dámaso García FraILE, en VV. AA, Las Edades del Hombre: el Árbol de la Vida, Valladolid, 2003, 84-86 y 419-421.

${ }^{9}$ Nos referimos, en concreto, a los fondos de las órdenes religiosas asentadas en la provincia segoviana, y, en el ámbito civil, al Archivo Histórico Provincial de Segovia e incluso al Archivo Histórico Nacional, instituciones donde debieron recabar algunas muestras en forma de guarda a protocolos notariales. En una visita a los PP. Jerónimos de Santa María de El Parral no pudimos localizar ningún fragmento; también solicitamos inspeccionar el archivo del monasterio de las Dominicas de Santo Domingo el Real, petición denegada por sus religiosas. 


\section{CRITERIOS DE CATALOGACIÓN}

A la hora de ordenar los manuscritos dentro del catálogo hemos adoptado el criterio cronológico, separando, eso sí, cada una de las instituciones investigadas en sendos epígrafes. El modelo de ficha propuesto se articula en cuatro apartados:

- Encabezamiento: incluye todos los datos que posibilitan la localización e identificación de cada fragmento: numeración currens, tipología del códice, datación, ocasión litúrgica y signatura topográfica. Asignamos un número currens con decimales a todos los fragmentos pertenecientes a un mismo códice, ordenando las distintas muestras según figurasen en el códice primigenio. Asimismo, con objeto de precisar la datación de los manuscritos empleamos las abreviaturas latinas in., med. o ex., siempre que haya seguridad para tal apreciación. Cuando los fragmentos sirven de guarda a alguno de los códices catalogados por Valverde ${ }^{10}$ o De los Reyes, ${ }^{11}$ ofrecemos la referencia de sus estudios debajo de la signatura topográfica del siguiente modo: [Cat. Incunables + número currens] en el caso de Valverde, y [Colecc. Arias Dávila + número de página] para De los Reyes.

- Descripción física del documento: de forma esquemática se ofrecen los siguientes datos: caracterización de la fuente, dimensiones, disposición del texto, número de líneas y medidas de la caja de escritura. Cuando los fragmentos actúan de guarda a un códice o incunable indicamos el título del mismo y su autor. Hemos resuelto, siempre que sea posible, facilitar en los bifolios la medida horizontal de todo el pliego por considerar esta información de mayor relevancia al tratarse de pergaminos sueltos. Asimismo, distinguimos entre líneas de texto, indistintamente si éstas están destinadas a albergar escritura alfabética o musical, caso de los manuscritos con notación aquitana; y renglones, en donde englobamos texto y música, caso de los fragmentos con notación cuadrada, donde la superficie ocupada por los pentagramas es mucho mayor a la del texto.

- Escritura, decoración y anotaciones marginales: se hace constar la variedad escrituraria empleada y su módulo, las letras capitales y su decoración, y las anotaciones al margen de tenor documental en caso de que las haya. Para el rango de las letras capitales hemos seguido el modelo propuesto por Hughes, ${ }^{12}$ de forma que consideramos mayúscula la letra que ocupa una o poco más de una línea de texto, calificando a las de mayor tamaño como iniciales. Aquellas iniciales que ocupan 3 o más líneas de texto son consignadas en las fichas como iniciales grandes.

\footnotetext{
${ }^{10}$ C. VAlVERDE DEL BARrio, Catálogo de Incunables y Libros Raros de la Santa Iglesia Catedral de Segovia, Segovia, 1930.

${ }^{11}$ Fermín de los ReYes Gómez, «El obispo bibliófilo: Arias Dávila y los libros», en VV. AA., Juan Parix: primer impresor en España, Segovia, 2004, 245-260.

12 A. Hughes, Medieval Manuscripts for Mass and Office: A guide to their organization and terminology, Toronto, 1982, 103-106.

Hispania Sacra, LXII

126, julio-diciembre 2010, 407-455, ISSN: 0018-215-X
} 
- Notación: informa de la variedad de escritura musical empleada y presencia de otros elementos auxiliares como claves, custos o dobles barras.

CATÁLOGO de FRAGMENTOS LITÚRgICO-MUSICALES

- Archivo de la Catedral de Segovia

$\mathrm{N}^{0} 1$ Breviarium, $\mathbf{s .}$ XII in.

No 1.1 (Hebdomadæ XVI-XVII post Pentecosten)

C-001

Bifolio visible sólo por su cara de carne adherido a la cara interior de un pergamino con función de guarda, 337 x 550 mm, 2 columnas, 40 líneas, caja de $180 \mathrm{~mm}$ de ancho.

Escritura carolina a dos módulos, el menor empleado en el texto musical. Mayúsculas sencillas en rojo o negro, los huecos de algunas mayúsculas rojas están rellenos con tinta amarilla. En el anverso del pergamino que sirve de carcasa se puede leer: «N. 3. L. C. Cajon. Acuerdos de el cavildo desde el año de 1321 asta 1415» y «Martín Domínguez Domingo. Andrés Alfonso Fernández. Cax 21»; en el reverso figura una relación de cuatro registros de actas capitulares.

Notación aquitana $(1 \mathrm{~mm})$ sobre pauta seca. Indica custos.

$\mathbf{N}^{0} 1.2$ (S. Laurentius)

C-008

Dos fragmentos pertenecientes a un mismo códice con función de guarda, 87 x $285 \mathrm{~mm}$ el mayor y 48 x $62 \mathrm{~mm}$ el menor; 2 columnas, 12 líneas el mayor y 1 el menor, imposible determinar las medidas de la caja de escritura.

Escritura carolina a dos módulos, el menor empleado en el texto musical. Inicial roja sencilla. Mayúsculas negras sencillas.

Notación aquitana $(1 \mathrm{~mm})$ sobre pauta seca. Indica custos.

\section{$\mathrm{N}^{0} 2$ Missale, $\mathbf{s}$. XII med.}

No 2.1 (SS. Marcus et Marcellianus / SS. Gervasius et Protasius / In Vigilia S. Joannis Baptistæ)

Folio con función de guarda, 325 x 235 mm, 2 columnas, 30 líneas, caja $250 \times 160 \mathrm{~mm}$. 
Escritura pregótica en el texto recitado y carolina en el musical, ésta última de menor módulo. Inicial grande sencilla en color rojo; iniciales rojas y azules embellecidas con filigrana roja, iniciales rojas y negras sencillas. Mayúsculas negras en el texto musical. Presenta varias anotaciones en el fol. r: «(...) 1532» en la parte superior izquierda; en la zona central superior «23»; en el centro del manuscrito en tinta azul «1(...)» tapado por la etiqueta de identificación del documento; en el área inferior derecha «1532», «Registro de cabildo años MDXXXII años, MDXXXIIII años, MDXXXV años, MDXXXVI años, Notario Diego de Guevara, MDXXXVII»; y a continuación en tinta azul «1532».

Notación aquitana $(1 \mathrm{~mm})$ sobre pauta seca. Indica custos.

$\mathbf{N}^{\circ} 2.2$ (SS. Vicentius Sabina et Christeta / SS. Claudius Lupercius et Victoricus / Quintinus / In Vigilia Omnium Sanctorum / Omnium Sanctorum / Albinus Martyr / Claudius Nichostratus Simpronianus Castorius et Simplicius)

Fragmento de bifolio con función de guarda, 258 x 443 mm, 2 columnas, 28 líneas, caja de $160 \mathrm{~mm}$ de ancho.

Escritura pregótica en el texto recitado y carolina en el musical, ésta última de menor módulo. Iniciales rojas y azules, algunas de las primeras están adornadas con filigrana roja; iniciales negras sencillas en el texto musical. Presenta varias anotaciones en la cubierta exterior (ff. 1r / 2v): «Diego de Guevara 1536. C 23» en el lateral izquierdo; en lápiz azul y por duplicado «1536», una junto a la anterior inscripción y otra en el lomo del documento, similar anotación en color negro se encuentra cerca del lomo; en el borde inferior y con escritura algo desgastada «Registro del Cabildo del año MDXXVI años». Otras anotaciones ilegibles.

Notación aquitana $(1 \mathrm{~mm})$ sobre pauta seca. Indica custos.

No 2.3 (In Vigilia S. Andreæ, Chrysanthus et Daria, S. Andreas)

Folio con función de guarda, 340 x 205 mm, 2 columnas, 32 líneas, caja de $240 \mathrm{~mm}$ de altura.

Escritura pregótica en el texto recitado y carolina en el musical, ésta última de menor módulo. Inicial azul con filigrana roja, iniciales rojas sencillas. Mayúsculas rojas y negras sencillas en el texto musical. Cubierta exterior sucia con algunos ensayos de pluma y anotaciones ilegibles.

Notación aquitana $(1 \mathrm{~mm})$ sobre pauta seca. Indica custos. 


\section{$\mathbf{N}^{\circ} 3$ Missale, $\mathbf{s}$. XII med.}

No 3.1 (Hebdomadæ III-IV post Pascha)

Bifolio con función de guarda, 345 x 485 mm, 2 columnas, 30 líneas, caja $250 \times 177 \mathrm{~mm}$.

Escritura pregótica a dos módulos, el menor empleado en el texto musical. Inicial grande ligeramente adornada en color rojo en el fol. 1v; iniciales rojas y azules con filigrana roja; iniciales rojas y negras sencillas. Numerosas anotaciones posteriores: «1531, Registro de Gabril (sic) de Guebara años de 1531, 1532, 1533. Obligaciones de los arrendatarios, poderes para cobrar N. 5. E.» en el fol. 2v; «muy magnifico señor los dias pasados sobreví a v. m. con (...) Antonio de Guadalajara nuestro hen [acaba aquí]» en el borde inferior derecho del fol. 2r; «muy magnificos señores la de Francisco de Laguna vezino desta çibdad besa las manos de v. m. y dize que (...) de la foz tiene (...)» en el margen derecho del fol. 1r. Numerosos ensayos de pluma y cuentas.

Notación aquitana (1 mm) sobre pauta seca. Indica custos.

No 3.2 (In Vigilia Ascensionis Domini / In Ascensione Domini / Dominica post Ascensionem)

Bifolio que actúa de guarda a un cuadernillo en el interior de un legajo, 315 x $500 \mathrm{~mm}, 2$ columnas, 30 líneas, caja 250 x $177 \mathrm{~mm}$.

Escritura pregótica a dos módulos, el menor empleado en el texto musical. Inicial grande enmarcada con motivos vegetales en colores verde y amarillo en el fol. 1v; iniciales rojas con filigrana roja y negra, iniciales rojas y azules con filigrana roja; iniciales rojas y negras sencillas. En el margen superior del fol. 1r se puede leer: «Juramentos para un otorgante Gabriel de Guevara»; otras anotaciones de compleja lectura. Varios ensayos de pluma y manchas.

Notación aquitana $(1 \mathrm{~mm})$ sobre pauta seca. Indica custos.

$\mathbf{N}^{\circ} 3.3$ (In Litania majore / Antiphonæ de Misericordia / Sabbato in Vigilia Pentecostes)

Bifolio suelto, 347 x 496 mm, 2 columnas, 30 líneas, caja 263 x 177 mm.

Escritura pregótica a dos módulos, el menor empleado en el texto musical. Iniciales rojas y azules con filigrana roja; iniciales rojas y negras 
sencillas. En el borde superior del fol. 1r se puede leer: «Aguilafuente Sotosalvos Pelayos»; otras anotaciones de compleja lectura. Varios ensayos de pluma.

Notación aquitana $(1 \mathrm{~mm})$ sobre pauta seca. Indica custos.

No 4 Missale, s. XII med. (Feria VI in Parasceve)

Bifolio suelto, 350 x 500 mm, 2 columnas, 30 líneas, caja 266 x 168 mm.

Escritura gótica a dos módulos, el menor empleado en el texto musical. Dos iniciales en color rojo, una de ellas con filigrana. Mayúsculas negras sencillas. En la cubierta exterior del manuscrito se advierten varias anotaciones de difícil lectura: en el borde inferior del fol. $2 \mathrm{v}$ «1538» $\mathrm{y}$ «Libro del pan año MDXXXVIII años», y en el margen inferior del fol. $1 \mathrm{v}$ «Libro del pan año MDXXXI años (...)».

Notación aquitana $(1 \mathrm{~mm})$ sobre pauta seca. Indica custos.

No 5 Rituale?, s. XII med. / ex. (Ordo pænitentiæ)

Fragmento de folio suelto, 148 x 230 mm, 2 columnas, 17 líneas, caja de $195 \mathrm{~mm}$ de ancho.

Escritura pregótica a dos módulos, el menor empleado en el texto musical. Inicial roja con filigrana, iniciales de menor tamaño en azul oscuro con filigrana roja. Mayúsculas negras sencillas en el texto musical.

Notación aquitana $(1 \mathrm{~mm})$ sobre línea gris marcada con plomo. Indica custos.

No 6 Breviarium, s. XII med. / ex. (S. Joannes Baptista / SS. Joannes et Paulus)

B. Garci Ruiz de Castro. Epítome auténtico

Dos fragmentos de folio adosados a las tapas del códice de Garci Ruiz de Castro: «Epitome auctenticorum-De heredibus et falcidia». Ambos folios debieron estar muy próximos en el códice primigenio pues hacen referencia a la misma festividad litúrgica, si bien no resultan parte superior e inferior de la misma cara. 143 x $198 \mathrm{~mm}$ (tapa anterior) y 143 × $201 \mathrm{~mm}$ (tapa posterior), 2 columnas, 20 líneas (tapa anterior) y 17 líneas (tapa posterior), imposible determinar las medidas de la caja de escritura.

Escritura pregótica a dos módulos, el menor empleado en el texto musical y parte de las rúbricas. Iniciales rojas y negras sencillas.

Notación aquitana $(1 \mathrm{~mm})$ sobre pauta seca. Indica custos. 
No 7 Missale, s. XII ex. (In Vigilia S. Joannis Baptistæ / S. Joannes Baptista / SS. Joannes et Paulus / S. Leo)

Museo 23

Bifolio suelto, 317 x 445 mm, 2 columnas, 30 líneas, caja 247 x 165 mm.

Escritura gótica en el texto recitado y pregótica en el musical; ésta última de menor módulo. Inicial grande con forma de hoja en colores rojo, verde y blanco; iniciales rojas y azules con filigrana roja; iniciales rojas sencillas. Mayúsculas negras sencillas.

Notación aquitana $(1 \mathrm{~mm})$ sobre pauta seca. Indica custos.

BiBL.: $\mathrm{n}^{\circ} 2$ en José JANINI, «Códices litúrgicos de la catedral de Segovia» Estudios Segovianos 15 (1963) 297-298.

No 8 Missale, s. XII ex. (Feriæ VI-Sabbato Hebdomadæ III Quadragesimæ / Feriæ III-IV Hebdomadæ IV Quadragesimæ)

\section{D. (sin signatura)}

Bifolio con función de guarda, 415 x 545 mm, 2 columnas, 36 líneas, caja $290 \times 190 \mathrm{~mm}$.

Escritura gótica en el texto recitado y pregótica en el musical, ésta última de menor módulo. Iniciales rojas y azul turquesas adornadas con filigrana, algunas combinan ambos colores. Mayúsculas negras sencillas. Numerosas anotaciones, la mayoría ilegibles: «pan 1553.» en la zona inferior central del fol. $2 \mathrm{v}$.

Notación aquitana $(1 \mathrm{~mm})$ sobre pauta seca. Indica custos.

No 9 Breviarium, s. XII ex. / s. XIII in. (Dominica III post Pascha)

Folio suelto, 442 x 310 mm, 2 columnas, 37 líneas, caja 380 x 250 mm.

Escritura gótica a dos módulos, el menor empleado en el texto musical. Inicial grande en color verde oscuro con filigrana roja; iniciales en colores rojo y verde oscuro con filigrana roja. Dos anotaciones en el fol. v: «1562» en el lateral izquierdo, y «Libro del año de MDLXII años» en el borde superior.

Notación aquitana $(1 \mathrm{~mm})$ sobre pauta gris marcada con plomo. Indica custos. 
$\mathbf{N}^{0} 10$ Breviarium, s. XII ex. / s. XIII in. (Dominica II Quadragesimæ)

Folio suelto, 490 x 314 mm, 2 columnas, 40 líneas, caja 359 x 226 mm.

Escritura gótica a dos módulos, el menor empleado en el texto musical. Iniciales rojas y azules de varios tamaños con filigrana roja, una de ellas antropomórfica; iniciales negras, algunas embellecidas con filigrana negra. Mayúsculas en azul oscuro o rojo con filigrana roja; mayúsculas negras sencillas. Anotación en el extremo inferior derecho del fol. $\mathrm{r}$ parcialmente ilegible: «Libro del pan del (...) año de (...) 1560».

Notación aquitana $(1 \mathrm{~mm})$ sobre pauta gris marcada con plomo. Indica custos.

$\mathrm{N}^{0} 11$ Breviarium, s. XII ex. / s. XIII in. (?)

A-185

[Cat. Incunables $n^{\circ} 328$ ]

Dos fragmentos de folio adheridos a modo de cartivana a las tapas del volumen segundo del incunable «Repertorium utriusque iuris» de Petrus de Monte, fechado en la segunda mitad del siglo XV. Apenas se puede leer una estrecha franja de $10 \mathrm{~mm}$ de ancho a ambos lados del lomo del libro. Imposible determinar número de líneas y si éstas son a escritura tirada o están distribuidas en columnas.

Escritura gótica a dos módulos, el menor empleado en el texto musical. No se observan iniciales.

Notación aquitana $(1 \mathrm{~mm})$ sobre pauta gris marcada con plomo. Imposible determinar la presencia de elementos auxiliares.

No 12 Breviarium, s. XII ex. / s. XIII in. / [Adición posterior, s. XIV]. (SS. Cornelius et Cyprianus / In Exaltatione Sanctæ Crucis)

[Colec. Arias Dávila, p. 248]

Dos fragmentos de folio adheridos a las tapas del códice de Buridanus «Qucestiones super X libros ethicorum Aristotelis» perteneciente a la colección del obispo Juan Arias Dávila (su ex-libris es visible en el fol. $1 \mathrm{r}$ del códice). Ambos fragmentos difieren en el sentido de escritura. 292 x $212 \mathrm{~mm}, 2$ columnas (tapa anterior) y escritura tirada (tapa posterior), 31 líneas más otra recortada (tapa anterior) y 26 líneas más otra recortada (tapa posterior), imposible determinar las medidas de la caja de escritura. 
Escritura gótica redonda a dos módulos, el menor empleado en el texto musical. Iniciales rojas sencillas. Mayúsculas negras sencillas.

Notación lorena in campo aperto y en tetragramas o pentagramas plasmados con tinta negra más diluida. Esta última modalidad de escritura musical ha sido añadida con posteridad y presenta claves de Fa, Do y Sol.

\section{$\mathrm{N}^{0} 13$ Breviarium, s. XII ex. / s. XIII in.}

No 13.1 (Feriæ IV-V Hebdomadæ I Adventus)

Folio con función de guarda, 520 × 357 mm, 2 columnas, 40 líneas, caja de $390 \mathrm{~mm}$ de altura.

Escritura gótica a dos módulos, el menor empleado en el texto musical. Iniciales azul turquesas y rojas adornadas con filigrana roja y violeta las primeras, y violeta y verde las segundas. Mayúsculas en el texto musical en colores rojo y azul turquesa, algunas de las primeras están adornadas con filigrana violeta. En el margen superior derecho del fol. $\mathrm{r}$ se puede leer: «Libro del pan de las cedulas ordinarias del año MDLXIIII años»; otras anotaciones de difícil lectura.

Notación aquitana $(1 \mathrm{~mm})$, no se distingue el pautado. Indica custos.

N 13.2 (In Decollatione S. Joannis Baptistæ)

Folio con función de guarda, 510 x 410 mm, 2 columnas, 40 líneas, caja 395 x $265 \mathrm{~mm}$.

Escritura gótica a dos módulos, el menor empleado en el texto musical. Iniciales verdes adornadas con filigrana roja y violeta. Mayúscula negra en el texto musical adornada con filigrana; mayúsculas rojas y negras sencillas. En el fol. v se advierten varias anotaciones, parte de ellas de difícil lectura: «Pitanças año del 1563» en el lateral superior izquierdo; algunas cuentas también en esta cara.

Notación aquitana $(1 \mathrm{~mm})$ sobre pauta gris marcada con plomo. Indica custos.

$\mathrm{N}^{0} 14$ Breviarium, s. XII ex. / s. XIII in.

$\mathbf{N}^{\mathbf{0}}$ 14.1 (Commune Apostolorum / Commune Unius Martyris)

B-400 (Tapa anterior)

[Colec. Arias Dávila, p. 253]

Bifolio con función de guarda al códice de Nicolaus de Tudeschis «Lectura super I parte libri i sexti Decretalium continens rubricas «De 
suma trinitate et fide catholica», "De constituniobus», «De postulate prcelatorum», «De electione et electi potestate»» perteneciente a la colección del obispo Juan Arias Dávila. 407 x 280 mm, 2 columnas, 39 líneas, caja $365 \times 230 \mathrm{~mm}$.

Escritura gótica redonda a dos módulos, el menor empleado en el texto musical y parte de las rúbricas. Iniciales de varios tamaños en azul turquesa, azul y rojo adornadas con filigrana roja las primeras, y azul las del último color. Mayúsculas rojas, azules y negras en el texto musical, algunas de este último color presentan puntos rojos.

Notación aquitana $(1 \mathrm{~mm})$ sobre pauta gris marcada con plomo. Indica custos.

$\mathbf{N}^{\mathbf{0}} \mathbf{1 4 . 2}$ (Commune Apostolorum)

B-441

Bifolio con función de guarda adherido a la tapa posterior del códice de Nicolaus de Tudeschis «Lectura super III libro Decretalium», fechado en el siglo XV. 404 x 290 mm, 2 columnas, 39 líneas, caja 365 x $240 \mathrm{~mm}$.

Escritura gótica redonda a dos módulos, el menor empleado en el texto musical. Iniciales verdes y azules adornadas con filigrana roja; iniciales de similares características de menor tamaño en colores verde y rojo con filigrana roja y azul respectivamente. Mayúsculas rojas y azules con filigrana en el texto musical; mayúsculas negras sencillas.

Notación aquitana $(1 \mathrm{~mm})$ sobre pauta gris marcada con plomo. Indica custos.

$\mathbf{N}^{0} 15$ Antiphonale officii, $\mathrm{s}$. XIII in. (In Epiphania Domini)

$153 / 6$

Fragmento de bifolio suelto, 430 x 285 mm, 2 columnas, 32 líneas, caja $300 \times 189 \mathrm{~mm}$.

Escritura gótica a dos módulos, el menor empleado en el texto musical. Iniciales rojas y amarillas sencillas; iniciales negras sencillas en el texto musical. Mayúsculas negras también en el texto musical. Anotación posterior en el margen superior izquierdo del fol. v: «Son apeos de Valseca de bohones».

Notación aquitana $(1 \mathrm{~mm})$ sobre pauta seca. Indica custos. 
$\mathbf{N}^{0} 16$ Missale, $\mathbf{s .}$ XIII in. (In Nativitate Domini)

B-304bis

Tres tiras de pergamino a modo de cartivana, 265 x 12-17 mm, 29 líneas, disposición del texto y medidas de la caja de escritura imposibles de determinar.

Escritura gótica dos módulos, el menor empleado en el texto musical. Iniciales rojas y violetas sencillas. Mayúsculas negras sencillas.

Notación aquitana $(1 \mathrm{~mm})$ sobre pauta seca. Indica custos.

No 17 Antiphonale officii, s. XIII in. / med.

$\mathbf{N}^{\mathbf{0}}$ 17.1 (S. Paulus / SS. Petrus et Paulus)

Museo 21

Folio suelto, 310 x $213 \mathrm{~mm}$, escritura tirada, 22 líneas, caja $230 \mathrm{x}$ $150 \mathrm{~mm}$. En el fol. $\mathrm{v}$ se aprecian más líneas debido a que hay una zona con el texto compactado.

Escritura gótica de similar módulo. Iniciales azules y rojas adornadas con filigrana roja y azul respectivamente; iniciales negras sencillas. Se advierten varias anotaciones especialmente en el borde inferior derecho del fol. v: «Çenso perpetuo de ¿Luis? de Tapia contra el concejo e vecinos del lugar de Mozonzillo es de la eredad que tenia en el Quadron porque paga en cada un año CCCXLI fanegas. Destas a de aver el cura de dicha Santa Iglesia de Segovia la CCXCI fanegas. El monasterio de San Francisco L fanegas. CCCXLI fanegas».

Notación aquitana (1’5 mm), no se distingue el pautado. Indica custos.

$\mathbf{N}^{\mathbf{0}}$ 17.2 (In Octava Apostolorum Petri et Pauli)

Museo 22

Folio suelto, $320 \times 223 \mathrm{~mm}$, escritura tirada, 22 líneas, caja $235 \mathrm{x}$ $150 \mathrm{~mm}$. En el fol. $\mathrm{v}$ se aprecian más líneas debido a que hay una zona con el texto compactado.

Escritura gótica de similar módulo. Iniciales rojas y azules embellecidas con filigrana azul y roja respectivamente; iniciales rojas sencillas. Mayúsculas negras sencillas. Se observa una anotación en el fol. r: «Censo perpetuo que otorgó el concejo de Moçonzillo a favor de Juan de Luna, de CXX fanegas de pan por mitad del término de Quadrón. Este censso le conpró el cavildo de Segovia y (...) pagar. Este (...) presentar en el (...) Es de la (...)».

Notación aquitana (1'5 mm), no se distingue el pautado. Indica custos. 
No 18 Missale, s. XIII in. / med. (In Vigilia S. Laurentii / S. Laurentius / S. Tiburtius)

Folio suelto, 300 x 196 mm, 2 columnas, 35 líneas, caja 260 x 166 mm.

Escritura gótica a dos módulos, el menor empleado en el texto musical. Iniciales rojas y azules adornadas con filigrana. Mayúsculas de similares características en el texto musical; mayúsculas sencillas en color negro.

Notación aquitana tendente a formas cuadradas $(1 \mathrm{~mm})$ sobre pauta gris marcada con plomo. Indica custos.

No 19 Breviarium, s. XIII med. (In Conceptione B. Mariæ)

D. Tazmías de Segovia 1568

Bifolio con función de guarda, 291 x 480 mm, escritura tirada, 24 líneas, caja 210 × $200 \mathrm{~mm}$.

Escritura gótica a dos módulos, el menor empleado en el texto musical. Iniciales rojas con filigrana, una de ellas de mayor tamaño. Mayúsculas rojas, algunas adornadas también con filigrana. Algunas anotaciones: parte superior del fol. 1r en letras de gran formato: «1568 prestamos»; margen inferior del fol. $2 \mathrm{v}$ «Las tazmias del arcedianato de Segovia 1568. Prestamos de 1568. Digo Tazmias». También en esta última cara varias anotaciones de difícil lectura: «Vicario (...) Señores Juan de $\mathrm{Sa}(\ldots)$. Al magnífico y revenrendísimo señor».

Notación aquitana tendente a formas cuadradas $(2 \mathrm{~mm})$ sobre pauta roja. Indica custos.

$\mathbf{N}^{0} 20$ Consuetudines ecclesia segobiensis, s. XIII med. (S. Jacobus / SS. Christophorus et Cucuphas / SS. Nazarius et Celsus / SS. Felix Simplicius et Faustinus / SS. Abdon et Sennen / Ad Vincula S. Petri / S. Felix / In Inventione S. Stephani / In Assumptione B. Mariæ / In Octava S. Laurentii / S. Agapitus / In Octava Assumptionis)

I. Cédulas ordinarias 1548

Bifolio con función de guarda, 318 x 464 mm, escritura tirada, 21 líneas, caja $275 \times 170 \mathrm{~mm}$.

Escritura gótica a dos módulos, el menor empleado en algunos íncipits de piezas musicales. Mayúsculas negras sencillas. Presenta varias anotaciones: en el borde inferior del fol. $2 \mathrm{v}$ «1548»; en el margen derecho zona central del fol. 1v «Villamayor»; otras anotaciones ilegibles. 
Notación aquitana (1'5 mm), no se distingue el pautado. No indica custos.

No 21 Antiphonale officii, s. XIII med. (Toni ad Invitatorium)

[Cat. Incunables $n^{\circ}$ 227-228]

Folio adherido a modo de cartivana a las tapas del incunable «Lectura super titulo de actionibus Institutionum / Lectura super titulo de apellationibus et relationibus», fechado en el siglo XV. 405 x $145 \mathrm{~mm}$ en cada tapa, 2 columnas, 34 líneas, imposible determinar las medidas de la caja de escritura.

Escritura gótica de similar módulo. Iniciales en rojo y azul violáceo adornadas con filigrana azul violácea y roja respectivamente; iniciales sencillas en color negro.

Notación cuadrada (2 $\mathrm{mm})$ sobre pauta roja. Indica custos.

$\mathbf{N}^{\circ} 22$ Graduale, s. XIII med.

No 22.1 (In Litania / In Nativitate Domini)

$153 / 9$

Folio suelto, 370 × $274 \mathrm{~mm}$, escritura tirada, recto 26 líneas y verso 28 líneas, caja 280 x $195 \mathrm{~mm}$.

Escritura gótica de similar módulo. Inicial grande en color azul con filigrana roja; inicial roja algo adornada. Mayúsculas sencillas o levemente adornadas en color rojo. Anotaciones ilegibles interlineales y marginales en el fol. r, especialmente en su lateral derecho.

Notación aquitana $(1 \mathrm{~mm})$ sobre pauta seca. Indica custos.

\section{No 22.2 (Sabbato Sancto / Dominica Resurrectionis)}

$153 / 10$

Folio suelto, 382 x 278 mm, escritura tirada, 26 líneas, caja 280 x 205 mm.

Escritura gótica de similar módulo. Inicial grande enmarcada rellena con filigrana en colores azul, rojo y oro; otras iniciales, dos de ellas adornadas con filigrana. Mayúsculas sencillas en colores rojo y negro. Anotaciones marginales ilegibles en el borde inferior del fol. v.

Notación aquitana $(1 \mathrm{~mm})$ sobre pauta seca. Indica custos. 
$\mathbf{N}^{0} 23$ Missale, s. XIII med. (Benedictus Abbas / In Annuntiatione B. Mariæ / SS. Tiburtius Valerianus et Maximianus)

Folio suelto, 322 × 219 mm, 2 columnas, 32 líneas, caja 272 x $182 \mathrm{~mm}$.

Escritura gótica a dos módulos, el menor empleado en el texto musical. Iniciales rojas y verdes con filigrana. Mayúsculas sencillas en color negro.

Notación aquitana tendente a formas cuadradas (1'5 mm) sobre pauta roja. Indica líneas divisorias y custos.

$\mathbf{N}^{\circ} 24$ Breviarium, s. XIII med. (S. Laurentius)

Folio con función de guarda, 550 x 400 mm, 2 columnas, 40 líneas, caja $420 \times 260 \mathrm{~mm}$.

Escritura gótica redonda a dos módulos, el menor empleado en el texto musical. Iniciales rojas con filigrana violeta, una de ellas presenta además tinta verde; iniciales negras con filigrana de idéntico color. Mayúsculas negras sencillas con los huecos rellenos con tinta violeta y amarilla. Numerosas anotaciones en el fol. v, la mayoría de difícil lectura: «Zedulas ordinarias de 1566» en el margen superior izquierdo, y «libro del pan de las cedulas hordinarias deste año de mill y quinientos y sesenta y seis años. 1566» en el borde inferior izquierdo. Numerosas manchas y ensayos de pluma en esta cara.

Notación aquitana $(1 \mathrm{~mm})$ sobre pauta gris marcada con plomo. Indica custos.

$\mathrm{N}^{\circ} 25$ Antiphonale officii ecclesice segobiensis, s. XIII ex. / $\mathrm{s}$. XIV in. $\mathbf{N}^{\circ} 25.1$ (In Traslatione S. Jacobi)

Museo 24

Folio suelto, $230 \times 327 \mathrm{~mm}$, escritura tirada, 10 líneas, caja de $255 \mathrm{~mm}$ de ancho.

Escritura gótica de similar módulo. Iniciales negras, una de ellas rellena con filigrana roja y negra. Mayúsculas sencillas en color negro.

Notación cuadrada $(3 \mathrm{~mm})$ sobre pauta roja. Indica custos.

No 25.2 (In Nativitate B. Mariæ / In Exaltatione Sanctæ Crucis)

Museo 25

Folio suelto, 459 x 319 mm, escritura tirada, 20 líneas, caja 338 x $255 \mathrm{~mm}$.

Escritura gótica de similar módulo. Iniciales rojas sencillas. Mayúsculas negras, algunas embellecidas con filigrana en sus huecos inte- 
riores. Varias anotaciones en el fol. v: «Gomezsarraçín papel del legajo ¿ $1^{\circ}$ ? cajon» en tinta desvaída, a continuación en tinta más oscura «93. Hai una carta sobre Novales acerca de lo qual hai despacho (...) Cax 60», ambas en el lateral derecho zona central inferior; « $\mathrm{CX}^{\circ}$ Gomezsarraçin diezmos personales fue librada executoria en favor del cavildo que es esta Gomezsarraçín « $\mathrm{y}$ « $\mathrm{n}^{\circ}$ 20» en el lateral superior izquierdo; «Gomezsarraçin es diezmos personales y una ca(...) r-30» en el borde inferior.

Notación cuadrada (3 mm) sobre pauta roja. Indica custos.

No 25.3 (Omnium Sanctorum / S. Martinus)

Museo 26

Folio suelto de formato irregular, 445 x $329 \mathrm{~mm}$, escritura tirada, 20 líneas, caja 352 x $240 \mathrm{~mm}$.

Escritura gótica a dos módulos, el menor empleado en las rúbricas más extensas. Iniciales rojas, una de ellas rellena con filigrana. Mayúsculas negras, una también embellecida con filigrana. Varias anotaciones en el fol. v: «Scrituras del cabildo de 1571. Cax 57» y «1571 anos», ésta última en letra de mayor tamaño, ambas en el lateral izquierdo; «Pedro Baca 1571 queda yndice. Caj. 22.» en la parte inferior derecha.

Notación cuadrada (3 $\mathrm{mm})$ sobre pauta roja. Indica custos.

$\mathbf{N}^{0} 25.4$ (S. Martinus)

Museo 27

Folio suelto, 474 x 335 mm, escritura tirada, 20 líneas, caja 336 x 247 mm.

Escritura gótica de similar módulo. Inicial grande roja levemente adornada en el fol. r; iniciales rojas sencillas. Mayúsculas negras, algunas embellecidas con filigrana. Varias anotaciones en el fol. v: «1522 N. 28 ¿ee?» en el lateral inferior y «1522» en tinta azul desvaída por la zona central inferior; una cuenta en el margen superior izquierdo de esta misma cara.

Notación cuadrada (3 mm) sobre pauta roja. Indica custos.

$\mathbf{N}^{\mathbf{0}} 25.5$ (S. Martinus / S. Bricius)

Museo 28

Dos folios sueltos cosidos por sus márgenes interiores, 382 × $338 \mathrm{~mm}$ el primero y 384 x $336 \mathrm{~mm}$ el segundo, escritura tirada, 20 líneas, caja 322 x $246 \mathrm{~mm}$ el primero y 332 × $253 \mathrm{~mm}$ el segundo. 
Escritura gótica de similar módulo. Iniciales rojas y negras sencillas. Mayúsculas negras, algunas embellecidas con filigrana. Presenta varias anotaciones: en el lateral derecho del fol. 1r «Reconocimientos de censos desde el año de 1569»; en la parte central izquierda del fol. $2 \mathrm{v}$ «Ano 1569 anos.»; abiertos los dos folios por la cara de carne (ff. 1r / 2v) se lee «Pedro Baca año 1569. Esta el yndice cosido al primer instrumento. N. 1. A. Caj. 22.» en el margen superior.

Notación cuadrada (3 mm) sobre pauta roja. Indica custos.

$\mathbf{N}^{0} 25.6$ (S. Cæcilia)

Museo 29

Folio suelto, 462 x 335 mm, escritura tirada, 20 líneas, caja 336 x 260 mm.

Escritura gótica de similar módulo. Iniciales rojas y negras, algunas embellecidas con filigrana. Mayúsculas negras sencillas. Varias anotaciones en el fol. $r$ : «Pedro Baca Instrumentos contenidos en los dos Indices cosidos en la $1^{\text {a }}$ Escriptura» en el lateral inferior derecho; «Scriptura del ano 1574 a 1577 (...)», «N. 3. C. Caj. 22» y «Caxon 5» en el borde inferior.

Notación cuadrada (3 mm) sobre pauta roja. Indica custos.

No 25.7 (S. Cæcilia / S. Clemens)

Museo 30

Folio suelto, 451 x $336 \mathrm{~mm}$, escritura tirada, recto 20 líneas y verso 18 líneas, caja 336 x $250 \mathrm{~mm}$.

Escritura gótica de similar módulo. Inicial grande en colores azul y rojo en el fol. v; iniciales rojas sencillas. Mayúsculas rojas y negras, algunas de este último color están embellecidas con filigrana. Presenta una anotación en el margen inferior izquierdo del fol. r: «N. 2. B.».

Notación cuadrada $(3 \mathrm{~mm})$ sobre pauta roja. Indica custos.

$\mathbf{N}^{\mathbf{0}} 25.8$ (Commune Unius Martyris)

Museo 32

Folio suelto, 451 x 311 mm, escritura tirada, 20 líneas, caja 354 x 254 mm.

Escritura gótica de similar módulo. Iniciales rojas y negras sencillas. Mayúsculas negras sencillas. En el fol. r figura una anotación en tinta negra: «Memorial de las scripturas de los diezmos».

Notación cuadrada (3 mm) sobre pauta roja. Indica custos. 
No 25.9 (Commune Plurimorum Martyrum)

Museo 31

Folio suelto, 477 x $332 \mathrm{~mm}$, escritura tirada, 20 líneas, caja 362 × $250 \mathrm{~mm}$.

Escritura gótica de similar módulo. Iniciales rojas sencillas. Mayúsculas negras, algunas embellecidas con filigrana. Varias anotaciones en el fol. r: en la parte superior central «N» al revés; en la parte superior derecha «Son de poca importancia» tachado, y a continuación «Y sobre presentar las Sacristias el señor Arcediano de Segovia», «Y sobre provision de sacristías por el señor Arcediano de Segovia»; más a la derecha respecto a las anteriores «Papeles tocantes a las Sacristias del Arcedianato de Segovia y otros papeles tocantes a residencia»; en el centro «Caxon diezmos y pleytos».

Notación cuadrada (3 mm) sobre pauta roja. Indica custos.

$\mathbf{N}^{0}$ 25.10 (Commune Plurimorum Martyrum / Commune Unius Confessoris)

Museo 33

Folio suelto, 294 x $327 \mathrm{~mm}$, escritura tirada, recto 13 líneas y verso 14 líneas, caja de $243 \mathrm{~mm}$ de ancho.

Escritura gótica de similar módulo. Iniciales rojas y negras sencillas. Mayúsculas negras sencillas. Se advierte una anotación en el margen superior del fol. $r$ : « $2^{\mathrm{a}}$. de San Andres».

Notación cuadrada $(3 \mathrm{~mm})$ sobre pauta roja. Indica custos.

$\mathbf{N}^{\mathbf{0}} 25.11$ (Commune Unius Confessoris)

Museo 34

Folio suelto, 360 × $326 \mathrm{~mm}$, escritura tirada, 20 líneas, caja de $242 \mathrm{~mm}$ de ancho.

Escritura gótica de similar módulo. Inicial grande en colores rojo, azul y negro; iniciales rojas y negras sencillas. Mayúsculas negras sencillas.

Notación cuadrada (3 mm) sobre pauta roja. Indica custos.

No 25.12 (Commune Unius Confessoris)

Museo 35

Folio suelto, 475 x 322 mm, escritura tirada, 20 líneas, caja 328 x $242 \mathrm{~mm}$.

Escritura gótica de similar módulo. Iniciales rojas y negras, algunas de este último color están embellecidas con filigrana. Mayúsculas ne- 
gras, algunas también adornadas con filigrana. Se aprecia una pequeña anotación ilegible en el lateral derecho zona central del fol. v, la cual posiblemente constituya un ensayo de pluma.

Notación cuadrada (3 mm) sobre pauta roja. Indica custos.

$\mathbf{N}^{0} 25.13$ (Commune Virginum)

153/18

Folio suelto de formato irregular, 320 × $329 \mathrm{~mm}$, escritura tirada, recto 15 líneas y verso 16 líneas, caja de $245 \mathrm{~mm}$ de ancho.

Escritura gótica a dos módulos, el menor empleado en las rúbricas. Iniciales rojas sencillas, una de ellas recortada. Mayúsculas negras, una embellecida con filigrana. En el margen superior del fol. $r$ se observa una anotación: «Fundación de una Capellanía en la Parroquia de San Millán de esta ciudad por Juan Álvarez».

Notación cuadrada (3 mm) sobre pauta roja. Indica custos.

$\mathbf{N}^{\mathbf{0}} 25.14$ (Pro Defunctis)

Museo 36

Folio suelto, 478 x 335 mm, escritura tirada, 20 líneas, caja 336 x $260 \mathrm{~mm}$.

Escritura gótica de similar módulo. Iniciales rojas sencillas. Mayúsculas negras, algunas embellecidas con filigrana.

Notación cuadrada $(3 \mathrm{~mm})$ sobre pauta roja. Indica custos.

No 25.15 (Pro Defunctis / Tonarium)

Museo 37

Folio suelto, 460 × $311 \mathrm{~mm}$, escritura tirada, recto 20 líneas y verso 24 líneas, caja 335 x $252 \mathrm{~mm}$.

Escritura gótica de similar módulo. Iniciales rojas sencillas. Mayúsculas negras sencillas.

Notación cuadrada $(3 \mathrm{~mm})$ sobre pauta roja. Indica custos.

$\mathbf{N}^{\mathbf{0}} \mathbf{2 5 . 1 6}$ (Tonarium)

Museo 38

Folio suelto, 442 × 314 mm, escritura tirada, 24 líneas, caja 352 × $250 \mathrm{~mm}$.

Escritura gótica de similar módulo. Inicial roja sencilla. Mayúsculas negras sencillas. En el margen izquierdo zona central del fol. $v$ se advierte una pequeña anotación apenas legible: «que me manda (...)»; algunos ensayos de pluma a continuación de esta anotación. 
Notación cuadrada (3 $\mathrm{mm})$ sobre pauta roja. Indica custos.

BiBL.: ${ }^{\circ} 8$ en José JANINI, «Códices litúrgicos de la catedral de Segovia» Estudios Segovianos 15 (1963) 302.

No 26 Missale, s. XIII ex. / s. XIV in. (In Epiphania Domini)

Dos folios adheridos a las tapas de un códice con obras de Boecio - - De consolatione philosophice» $\mathrm{y}$ «De scolastica disciplini»-, Virgilio - «Eneida»- y Ovidio. Imposible determinar si ambos folios pertenecen a un mismo bifolio. 295 x $170 \mathrm{~mm}$ (tapa anterior) y 299 × $175 \mathrm{~mm}$ (tapa posterior), escritura tirada, 13 líneas más otra recortada en ambos folios, caja de $138 \mathrm{~mm}$ de ancho.

Escritura gótica de similar módulo. Iniciales rojas sencillas. Mayúsculas violetas sencillas. Varias anotaciones apenas legibles en letra de pequeño formato por ambos folios.

Notación cuadrada (4 mm) sobre pauta roja. No indica custos.

No 27 Antiphonale officii, s. XIV. (Toni ad Invitatorium)

B-400 (Tapa posterior)

[Colec. Arias Dávila, p. 253]

Bifolio recortado que sirve de guarda a la tapa posterior del códice de Nicolaus de Tudeschis «Lectura super I parte libri i sexti Decretalium continens rubricas «De suma trinitate et fide catholica», «De constituniobus», «De postulate pralatorum», «De electione et electi potestate»» perteneciente a la colección del obispo Juan Arias Dávila. El fol. 2v está adherido a la tapa del códice por lo que resulta imposible su inspección. 407 x $280 \mathrm{~mm}$, escritura tirada, 6 renglones más otro recortado, imposible determinar las medidas de la caja de escritura.

Escritura gótica de similar módulo. Mayúsculas negras sencillas.

Notación cuadrada (5 mm) sobre pentagrama rojo. Indica custos, claves y líneas divisorias.

No 28 Breviarium, s. XIV (Dominicæ III-IV Quadragesimæ / Dominica de Passione)

D. Tazmías de Sepúlveda 1574

Bifolio con función de guarda, 296 x 510 mm, escritura tirada, 8 renglones, caja 235 x $165 \mathrm{~mm}$. 
Escritura gótica redonda a dos módulos, el menor empleado en las rúbricas. Iniciales negras quebradas; algunos cantos carecen de inicial. Presenta algunas anotaciones: «Tazmías 1574» en el borde superior del fol. $1 \mathrm{v}, \mathrm{y}$ «Sep. 1574» en el margen inferior del fol. 2r.

No incluye notación.

$\mathbf{N}^{\circ} 29$ Antiphonale officii, s. XIV ex. / s. XV in. (Dominica I post Epiphaniam)

153/16

Fragmento de folio suelto de formato irregular, $220 \times 145 \mathrm{~mm}$, escritura tirada, 4 renglones y medio, imposible determinar las medidas de la caja de escritura.

Escritura gótica de similar módulo. Se observa parte de una inicial roja enmarcada con filigrana violeta.

Notación cuadrada (5 $\mathrm{mm}$ ) sobre pentagrama rojo. Indica custos, claves, líneas divisorias y doble barra.

$\mathbf{N}^{0} 30$ Antiphonale officii, s. XIV ex. / s. XV in. (Dominica per annum)

Museo 40

Folio suelto, $230 \times 357 \mathrm{~mm}$, escritura tirada, 4 renglones y medio, caja de $220 \mathrm{~mm}$ de ancho.

Escritura gótica de similar módulo. Iniciales enmarcadas con filigrana en colores azul oscuro, rojo y violeta. En el margen inferior izquierdo del fol. v figura la siguiente anotación: «Caj. 76. Martin Miguel. Censos, y arriendos temporales».

Notación cuadrada (5 mm) sobre pentagrama rojo. Indica custos, claves y líneas divisorias.

$\mathbf{N}^{0} 31$ Antiphonale officii, s. XV. (In Natale Innocentium)

Museo 39

Folio suelto, $240 \times 328 \mathrm{~mm}$, escritura tirada, 3 renglones y medio, caja de $230 \mathrm{~mm}$ de ancho.

Escritura gótica de similar módulo. Inicial enmarcada con filigrana en colores rojo y azul; inicial negra quebrada. En el fol. v se observan dos anotaciones: «Sr. Miguel de Párraces» en el lateral izquierdo y «Miguel Párraces» en el margen inferior derecho.

Notación cuadrada $(5 \mathrm{~mm})$ sobre pentagrama rojo. Indica custos, claves y líneas divisorias. 
$\mathbf{N}^{\mathbf{0}} 32$ Antiphonale officii, s. XV. (De Sanctis Tempore Paschali)

\section{Tazmías de Segovia 1583}

Fragmento de bifolio con función de guarda, 495 x $585 \mathrm{~mm}$, escritura tirada, 7 renglones, imposible determinar las medidas de la caja de escritura.

Escritura gótica a dos módulos, el menor empleado en las rúbricas. Iniciales rojas sencillas y negras quebradas. Algunas anotaciones en la cubierta exterior: en la parte superior del fol. $1 \mathrm{v}$ coincidiendo con el doblez del bifolio «tazmias del arcedianato de segovia del año MDLXXXIII», apenas legible al estar raspadas las letras; «Prestamos 1583 para 1584», «Don Juan de Mendoca (...)» y «Muy magnifico señor Alonso de (...)» en el fol. 2 r, las dos últimas resultan de compleja lectura; cuentas en la esquina superior derecha de esta última cara.

Notación cuadrada $(6 \mathrm{~mm})$ sobre pentagrama rojo. El himno Tristes erant apostoli presenta notación mensural. Indica custos, claves y líneas divisorias.

No 33 Antiphonale officii, s. XV. (S. Petrus)

\section{Tazmías de Segovia 1585}

Folio con función de guarda, 500 x 313 mm, escritura tirada, 7 renglones, caja 370 x $220 \mathrm{~mm}$.

Escritura gótica de similar módulo. Iniciales negras quebradas. Algunas anotaciones en el fol. v: «tazmias de el arcedianato de Segovia MDLXXXV» en el extremo superior izquierdo y «1585» en el lateral inferior derecho; una cuenta apenas legible en el margen inferior izquierdo de esta misma cara.

Notación cuadrada (7 mm) sobre pentagrama rojo. Indica custos, claves, líneas divisorias y doble barra.

No 34 Breviarium?, s. XV. (Feria VI in Parasceve)

D. Tazmías de Segovia 1587

Folio con función de guarda, 532 x 380 mm, escritura tirada, imposible determinar el número de renglones, caja 390 x $220 \mathrm{~mm}$.

Escritura gótica de similar módulo. Iniciales azules y rojas enmarcadas con filigrana roja y violeta respectivamente; una inicial negra quebrada. Mayúsculas sencillas en color rojo. Algunas anotaciones en el fol. v: «Tazmias del arcedianato de Segovia, ano de MDLXXXVII. Tazmias de 1587» en el extremo inferior derecho; diversas cuentas distribuidas por toda la superficie de esta cara. 
Notación cuadrada $(6 \mathrm{~mm})$ sobre pentagrama rojo. Indica custos, claves, líneas divisorias y doble barra.

No 35 Breviarium, s. XV. (In Nativitate Domini)

D. Tazmías de Segovia 1590

Folio con función de guarda, 530 x 375 mm, escritura tirada, 10 renglones, caja 320 x $235 \mathrm{~mm}$.

Escritura gótica a dos módulos, el menor empleado en algunas rúbricas. Iniciales azules y rojas enmarcadas con filigrana roja y violeta respectivamente; una inicial negra quebrada. Mayúsculas azules y rojas enmarcadas con filigrana roja y violeta respectivamente. Algunas anotaciones en el fol. v: en el extremo superior izquierdo «Tazmias de el Arcedianato de Segovia de el año de 1590. Están en este atado los libros de tazmias de los años siguientes: ano de 1590, 1591, 1592, 1593, 1594, $1595,1598,1603,1605,1607,1608,1609 »$; en el margen inferior izquierdo «Tazmias de Segovia de frutos de. 90. que son para, año de. 91.» $\mathrm{y} \ll 1590$ para $1591 »$.

Notación cuadrada (5 mm) sobre pentagrama rojo. Indica custos, claves, líneas divisorias y doble barra.

No 36 Graduale, s. XV. (In Traslatione S. Jacobi / Pro Virgine et Martyre)

\section{Tazmías de Segovia 1592}

Folio con función de guarda, 520 x 309 mm, escritura tirada, 10 renglones, caja de $400 \mathrm{~mm}$ de alto.

Escritura gótica a dos módulos, el menor empleado en algunas rúbricas. Iniciales azules y rojas enmarcadas con filigrana roja y azul respectivamente; iniciales negras quebradas. Algunas anotaciones en el fol r.: «tazmias del arcedianato de Segovia de los frutos de noventa y uno que sirven para. 92. 1592» en el margen superior derecho; «1591» en azul en el lateral derecho zona inferior. Cuentas y ensayos de pluma por ambas caras.

Notación cuadrada (5 mm) sobre pentagrama rojo. Indica custos, claves, líneas divisorias y doble barra.

$\mathbf{N}^{\circ} 37$ Antiphonale officii, s. XV. (Cathedra S. Petri)

D. Tazmías de Cuellar 1585

Dos folios procedentes del mismo códice cosidos por sus márgenes interiores con función de guarda, 475 x $290 \mathrm{~mm}$ cada folio, escritura tirada, 6 renglones, caja $285 \times 220 \mathrm{~mm}$. 
Escritura gótica a dos módulos, el menor empleado en las rúbricas. Iniciales azules y rojas enmarcadas con filigrana roja y azul respectivamente; iniciales negras quebradas. Numerosas anotaciones en la cubierta exterior: «Cuellar. Tazmias. MDLXXXV: 1585» en la zona inferior del fol. 1v, varias cuentas en los bordes interiores de este folio; en el margen superior del fol. $2 \mathrm{r}$ «Libro de tazmias deste año de mil y quinientos y ochenta y çinco años del arcedianazgo de Cuellar. Fecho por Alonso ¿Matheo? vezino de Segobia», en el cuerpo central de este folio «Muy magnifico señor Alonso Martinez» junto a otras anotaciones de compleja lectura con apariencia de ensayos de pluma.

Notación cuadrada $(5 \mathrm{~mm})$ sobre pentagrama rojo. Indica custos, claves y líneas divisorias.

$\mathbf{N}^{\mathbf{0}} 38$ Breviarium, s. XV. (Feria VI in Parasceve)

D. Tazmías de Cuellar 1592

Folio con función de guarda, 480 x 305 mm, recto 3 renglones y 18 líneas y verso 8 renglones, caja 385 x $235 \mathrm{~mm}$.

Escritura gótica de similar módulo. Iniciales en colores azul, rojo y negro, la de color rojo está embellecida con filigrana violeta. Algunas anotaciones en el fol. v: «tazmias del partido de cuellar de los frutos de noventa y dos. 1592» en la parte superior izquierda; y en la inferior izquierda «Blas G(...)lez» escrito varias veces junto a otras palabras ilegibles. Varias cuentas por ambas caras.

Notación cuadrada $(5 \mathrm{~mm})$ sobre pentagrama rojo. Indica custos, claves, líneas divisorias y doble barra.

\section{$\mathbf{N}^{0} 39$ Antiphonale officii, $\mathrm{s} . \mathrm{XV}$.}

No 39.1 (S. Jacobus)

Fragmento de folio con función de guarda a un cuadernillo que contiene la voz de tiple $1^{\circ}$ del coro $1^{\circ}$ de misas polifónicas de Gandulañ, Labeaga, Robledo y Vargas..$^{13} 340$ x $223 \mathrm{~mm}$, escritura tirada, 6 renglones, imposible determinar las medidas de la caja de escritura.

Escritura gótica redonda de similar módulo. Una inicial roja sencilla y otra negra quebrada.

13 Acerca de la misas polifónicas véase J. López-CAlo, La Música en la Catedral de Segovia, vol. 2, Segovia, 1988. Gandulañ, n 3602, 232; Labeaga, n 3636, 275; Robledo, n 3956, 344-345; Vargas, $\mathrm{n}^{\mathrm{o}} 4095,392$. 
Notación cuadrada $(5 \mathrm{~mm})$ sobre pentagrama rojo. Indica custos, claves y líneas divisorias.

$\mathbf{N}^{0} 39.2$ (S. Andreas)

$83 / 6$

Fragmento de folio con función de guarda a un cuadernillo que contiene la voz de tiple $2^{\circ}$ o tenor del coro $2^{\circ}$ de misas polifónicas de Gandulañ, Labeaga, Robledo y Vargas. 215 x $342 \mathrm{~mm}$, escritura tirada, recto 3 renglones y medio y verso 4 renglones y medio, caja de $240 \mathrm{~mm}$ de ancho.

Escritura gótica redonda de similar módulo. Inicial grande en colores azul y rojo enmarcada con filigrana; iniciales negras quebradas.

Notación cuadrada $(5 \mathrm{~mm})$ sobre pentagrama rojo. Indica custos, claves, líneas divisorias y doble barra.

$\mathbf{N}^{0} 39.3$ (S. Andreas)

83/8bis

Fragmento de folio con función de guarda a un cuadernillo que contiene la voz de bajo del coro $2^{\circ}$ de misas polifónicas de Gandulañ, Labeaga, Robledo y Vargas. 219 x 333 mm, escritura tirada, 3 renglones y medio, caja de $250 \mathrm{~mm}$ de ancho.

Escritura gótica redonda a dos módulos, el menor empleado en las rúbricas. Una inicial sencilla azul oscuro y otra negra quebrada.

Notación cuadrada $(5 \mathrm{~mm})$ sobre pentagrama rojo. Indica custos, claves, líneas divisorias y doble barra.

No 39.4 (S. Andreas / S. Lucia)

$83 / 7$

Fragmento de folio con función de guarda a un cuadernillo que contiene la voz de tiple $3^{\circ}$ del coro $2^{\circ}$ de misas polifónicas de Gandulañ, Labeaga, Robledo y Vargas. 220 × $332 \mathrm{~mm}$, escritura tirada, 4 renglones, caja de $240 \mathrm{~mm}$ de ancho.

Escritura gótica redonda a dos módulos, el menor empleado en algunas rúbricas. Dos iniciales en colores azul y rojo, una de ellas embellecida con filigrana.

Notación cuadrada (5 $\mathrm{mm}$ ) sobre pentagrama rojo. Indica custos, claves, líneas divisorias y doble barra. 
No 39.5 (S. Lucia / S. Andreas)

Fragmento de folio con función de guarda a un cuadernillo que contiene la voz de alto del coro $2^{\circ}$ de misas polifónicas de Gandulañ, Labeaga, Robledo y Vargas. 214 x $331 \mathrm{~mm}$, escritura tirada, 3 renglones y medio, caja de $245 \mathrm{~mm}$ de ancho.

Escritura gótica redonda de similar módulo. Inicial negra quebrada. En el borde inferior izquierdo del fol. v figura una anotación: «Misa Robledo».

Notación cuadrada (5 mm) sobre pentagrama rojo. Indica custos, claves, líneas divisorias y doble barra.

$\mathbf{N}^{\mathbf{0}} 40$ Antiphonale officii?, s. XV. (Hymnus: Te Matrem Dei laudamus)

I. Cédulas ordinarias 1556

Fragmento de folio con función de guarda, 515 x $395 \mathrm{~mm}$, escritura tirada, 8 renglones, caja 340 × $230 \mathrm{~mm}$.

Escritura gótica de similar módulo. Mayúsculas sencillas en color negro. En el fol. v se advierten varias anotaciones: «Libro del Pan que se repartió el Año 1556» y en un tamaño mayor «1556», ambas en el lateral inferior derecho; otra anotación ilegible en el borde inferior izquierdo que podría ser un ensayo de pluma; en el doblez de esta cara zona superior se observan diversos ensayos de pluma. En el fol. $r$ se puede leer: «En 5 de julio de 1555 dieron poder para cobrar el pan» y «En 10 de julio de 1555 dieron poder para cobrar el pan así trigo como cevada», ambas en la zona inferior izquierda; varios ensayos de pluma en la zona superior derecha de esta última cara.

Notación cuadrada (5 mm) sobre pentagrama rojo. Indica custos, claves, líneas divisorias y doble barra.

No 41 Graduale, s. XV. (Pentecoste / Feria II Pentecostes)

Folio suelto, 514 x $369 \mathrm{~mm}$, escritura tirada, 8 renglones, caja 380 x $235 \mathrm{~mm}$.

Escritura gótica de similar módulo. Iniciales enmarcadas con filigrana en colores azul, rojo y violeta; iniciales negras quebradas.

Notación cuadrada (5 mm) sobre pentagrama rojo. Indica custos, claves, líneas divisorias y doble barra. 
$\mathrm{N}^{\mathrm{o}} 42$ Antiphonale officii, $\mathrm{s.}$ XV med.

$\mathbf{N}^{\circ}$ 42.1 (In Purificatione B. Mariæ)

$153 / 12$

Fragmento de bifolio suelto, 282 × $686 \mathrm{~mm}$, escritura tirada, 3 renglones, caja de $223 \mathrm{~mm}$ de ancho.

Escritura gótica de similar módulo. Inicial roja enmarcada con filigrana violeta; iniciales negras quebradas.

Notación cuadrada $(6 \mathrm{~mm})$ sobre pentagrama rojo. Indica custos, claves y líneas divisorias.

$\mathbf{N}^{0}$ 42.2 (In Purificatione B. Mariæ)

$\mathrm{N}^{\circ}$ 42.2a [Anexo] Antiphonale officii, s. XIV ex. / s. XV in. (Dominica per annum)

$153 / 13$

Fragmento de bifolio suelto, 270 x $750 \mathrm{~mm}$, escritura tirada, 3 renglones, caja de $225 \mathrm{~mm}$ de ancho. Cosido en un lateral se halla un pequeño fragmento de antifonario: 200 x $178 \mathrm{~mm}$, escritura tirada, 4 renglones y medio, imposible determinar las medidas de la caja de escritura.

Escritura gótica de similar módulo. En el fragmento principal se aprecia una inicial roja con filigrana violeta muy desvaída y varias iniciales negras quebradas; en el fragmento anexo figura una inicial negra quebrada.

Notación cuadrada $(6 \mathrm{~mm})$-en el anexo $5 \mathrm{~mm}$ - sobre pentagrama rojo. Ambos fragmentos indican custos, claves y líneas divisorias.

No 43 Antiphonale officii, s. XV. (Feria V in Cœna Domini / Feria VI in Parasceve)

\section{Tazmías de Sepúlveda 1582}

Folio con función de guarda, 550 x $408 \mathrm{~mm}$, escritura tirada, 8 renglones, caja 380 x $240 \mathrm{~mm}$.

Escritura gótica a dos módulos, el menor empleado en algunas rúbricas. Inicial azul enmarcada con filigrana roja; iniciales rojas y negras sencillas. Mayúsculas negras sencillas. Algunas anotaciones en el fol. r: «Tazmias de Sepulveda MDXXXII» en el lateral superior derecho, y «1582» en el borde superior izquierdo.

Notación cuadrada $(6 \mathrm{~mm})$ sobre pentagrama rojo. Indica custos, claves, líneas divisorias y doble barra. 
$\mathbf{N}^{\circ} 44$ Antiphonale officii, s. XV. (Dominica per annum)

Fragmento de bifolio suelto, 454 x $233 \mathrm{~mm}$, escritura tirada, 8 renglones, caja de $355 \mathrm{~mm}$ de altura.

Escritura gótica de similar módulo. Iniciales azules y rojas enmarcadas con filigrana roja y violeta respectivamente; varias iniciales negras quebradas con los huecos interiores coloreados en amarillo y violeta. Mayúsculas negras sencillas.

Notación cuadrada (5 mm) sobre pentagrama rojo. Indica custos, claves, líneas divisorias y doble barra.

No 45 Hymnarium, s. XV. (Tempus Quadragesimæ)

I. Cédulas ordinarias 1569

Fragmento de bifolio con función de guarda, 480 x $575 \mathrm{~mm}$, escritura tirada, 10 renglones, caja de $275 \mathrm{~mm}$ de ancho.

Escritura gótica de similar módulo. Iniciales azules enmarcadas con filigrana roja. Mayúsculas azules y rojas enmarcadas con filigrana roja y violeta respectivamente, la filigrana de algunas mayúsculas rojas aparece desvaída. Algunas anotaciones en la cubierta exterior: «libro de las cedulas del pan deste de MDLXIX. 1569» en el extremo inferior del bifolio. Otras anotaciones en el fol. 2v: «Cedulas ordinarias 1569» en la parte inferior, y «luz perpetua» a modo de ensayo de pluma un poco más arriba. En el doblez del bifolio hay varias cuentas y ensayos de pluma. En el margen interior del fol. 1r se observa: «dixi (...) dominus domino meo sedde a» flanqueado por diversos ensayos de pluma.

Notación cuadrada (5 mm) sobre pentagrama rojo. Indica custos, claves, líneas divisorias y doble barra.

No 46 Breviarium, s. XV (S. Blasius)

\section{Registro de censos 1554-1556}

Fragmento de folio con función de guarda, 480 x $338 \mathrm{~mm}$, escritura tirada, imposible determinar el número de renglones, caja 315 x $200 \mathrm{~mm}$.

Escritura gótica de similar módulo. Inicial grande enmarcada con filigrana en colores azul, rojo y violeta; iniciales azules y rojas enmarcadas con filigrana roja y violeta respectivamente; varias iniciales negras quebradas. El fragmento presenta numerosas anotaciones sobre todo en su cubierta exterior: en el lateral inferior izquierdo «Registro de censos de los años de 1555: 1556» en tinta desvaída, y al lado «Pedro Martínez y 
otros»; en el lateral superior izquierdo «1554. 1555/ 1556»; en el extremo superior derecho «Son las mas de ellas de Pedro Martínez» y «N. 7. $A »$. En el margen superior izquierdo del fol. v: «muy magnifico»; varios ensayos de pluma en esta última cara.

Notación cuadrada (4 mm) sobre pentagrama rojo. Indica custos, claves, líneas divisorias y doble barra.

No 47 Antiphonale officii, s. XV (In Natale Innocentium)

Folio con función de guarda, 450 x $317 \mathrm{~mm}$, escritura tirada, 8 renglones, caja $360 \times 225 \mathrm{~mm}$.

Escritura gótica de similar módulo. Inicial azul enmarcada con filigrana roja; iniciales negras sencillas con los huecos interiores rellenos con tinta violeta y amarilla. Mayúsculas de similares características a las iniciales. Algunas anotaciones en el margen superior izquierdo del fol. r: «Espolio del señor obispo don Antonio Ydiaquez», «Caj. 2, Legajo $\mathrm{N}^{\circ}$ 15», «fabrica, casulla, pontifical», «Auto por los quales a la fabrica se entrego el pontifical y casulla que quedo del señor obispo don Antonio Ydiaquez» $\mathrm{y}$ « $\mathrm{N}^{\circ}$ 62».

Notación cuadrada (5 $\mathrm{mm}$ ) sobre pentagrama rojo. Indica custos, claves, líneas divisorias y doble barra.

No 48 Rituale?, s. XV (Ordo chrismalis)

\section{Estatutos (sin signatura)}

Bifolio con función de guarda, 315 x 447 mm, escritura tirada, 6 renglones, caja 215 x $130 \mathrm{~mm}$.

Escritura gótica de similar módulo. Inicial azul con filigrana roja; inicial roja sencilla; iniciales negras quebradas. Ensayos de pluma y cuentas

Notación cuadrada (3 mm) sobre pentagrama rojo. Indica custos, claves, líneas divisorias y dobles barras.

$\mathbf{N}^{\circ} 49$ Antiphonale officii, s. XV med. / ex. (In Annuntiatione B. Mariæ)

$153 / 14$

Folio suelto, 544 x $314 \mathrm{~mm}$, escritura tirada, 7 renglones, caja 345 x $224 \mathrm{~mm}$.

Escritura gótica de similar módulo. Iniciales azules y rojas con filigrana roja y violeta respectivamente, la filigrana violeta aparece muy desvaída; iniciales negras quebradas.

Notación cuadrada $(6 \mathrm{~mm})$ sobre pentagrama rojo. Indica custos, claves, líneas divisorias y doble barra. 
$\mathbf{N}^{0} 50$ Antiphonale officii, s. XV ex. / s. XVI in. (Dominica Sexagesimæ?)

\section{Tazmías de Sepúlveda 1575}

Fragmento de folio con función de guarda, 308 x $493 \mathrm{~mm}$, escritura tirada, 2 pentagramas en la cubierta exterior y 6 líneas de texto en la cubierta interior, caja de $342 \mathrm{~mm}$ de ancho.

Escritura gótica a dos módulos, el menor empleado en las rúbricas. Mayúsculas negras sencillas. Numerosas anotaciones en ambas caras: «1575» en el borde superior derecho de la cara de pelo, numerosas cuentas a lo largo de esta cara; en la cara de carne se aprecian varios ensayos de pluma y dos dibujos, el primero muestra un caballero cortesano con espada en mano y el segundo un guitarrista; en la zona inferior izquierda de esta última cara se puede leer «Antonio de Parrua»y «para Amenquerer».

Notación cuadrada (10-11 mm) sobre pentagrama rojo. Indica custos, claves, líneas divisorias y doble barra.

$\mathbf{N}^{0} 51$ Antiphonale officii, s. XV ex. / s. XVI in. (Ad dimissionem: Benedicamus Domino)

Fragmento de folio suelto, 425 x $498 \mathrm{~mm}$, escritura tirada, 3 renglones, caja de $360 \mathrm{~mm}$ de ancho.

Escritura gótica a dos módulos, el menor empleado en las rúbricas. Iniciales azules y rojas enmarcadas con filigrana roja y azul respectivamente. Numerosas anotaciones en la cara de carne: «Censo de Quint. ${ }^{a}$ de Arriva (...) enfiteutico» en el margen superior izquierdo; «Zenso a favor de esta (...) de 30 fanegas de pan, trigo y zebada por mitad, contra ciertos vezinos de Quintanilla de Arriva, es perpetuo» en el lateral derecho; «N. 2 B», «Caxon 10. Seg 9», «Reconociose el año de 1770 y está inserto el reconocimiento hecho ante Francisco Martinez ¿secretario? de Padilla» y « $\mathrm{N}^{\circ} 53 »$ en la esquina inferior izquierda; varias cuentas en el doblez del lateral derecho de esta cara.

Notación cuadrada $(12 \mathrm{~mm})$ sobre pentagrama rojo. Indica custos, claves y dobles barras.

$\mathbf{N}^{0} 52$ Antiphonale officii, s. XV ex. / s. XVI in. (S. Joannes Evangelista)

F-148

Fragmento de folio con función de guarda, 430 x 300 mm, escritura tirada, 8 renglones, caja de $358 \mathrm{~mm}$ de altura. 
Escritura gótica de similar módulo. Inicial roja con filigrana azul; iniciales negras quebradas con los huecos rellenos con tinta amarilla y violeta. En el borde inferior derecho del fol. $r$ se lee: «Concordia entre los señores dean y cavildo de la santa Yglessia de Segovia $n^{\circ} 27$ con el señor Don Cristoval Bernardo de Quiros dean de la dicha santa Yglessia sobre nonbrar presidente. Año de 1607»; en tinta desvaída «Valde Donorandus» justo encima de la anotación previa.

Notación cuadrada $(6 \mathrm{~mm})$ sobre pentagrama rojo. Indica custos, líneas divisorias y doble barra.

No 53 Antiphonale officii, s. XVI (In Purificatione B. Mariæ)

G-68 (25)

Fragmento de folio con función de guarda, 445 x $312 \mathrm{~mm}$, escritura tirada, 5 renglones y medio, imposible determinar las medidas de la caja de escritura.

Escritura gótica de similar módulo. Inicial azul con filigrana roja. En el borde inferior derecho de la cara de carne se lee: «Caj. 1 Fabrica Leg. 8. N. 11. Pleitos. Çedula real en que su magestad hace limosna a la fabrica de esta santa Iglessia de quinientos ducados en cada un año por cinco años corren desde el de 1631. Echado y repartido en sissas en esta ciudad de Segovia», en posición más central y por duplicado « $\mathrm{N}^{\circ} 30 »$.

Notación cuadrada (6 mm) sobre pentagrama rojo. Indica custos, claves, líneas divisorias y doble barra.

- Archivo del Convento de San José (Carmelitas descalzas)

No 54 Breviarium, s. XII med. (Dominica Quinquagesimæ / Dominica I Quadragesimæ / Feria II Hebdomadæ I Quadragesimæ)

Tabla 0-A

Bifolio suelto, 320 x 449 mm, 2 columnas, 33 líneas, caja de 175 mm de ancho.

Escritura pregótica a dos módulos, el menor empleado en el texto musical. Iniciales sencillas en colores rojo o negro. Mayúsculas sencillas también en rojo o negro. En el margen izquierdo del fol. 1v se aprecian restos de texto y notación musical contemporáneos a la escritura del fragmento. En el fol. 1r se observan las siguientes anotaciones: «1529» en la esquina superior derecha, y a continuación «Prado nuevo. Colmenar». En la esquina superior izquierda del fol. $2 \mathrm{v}$ se advierte una anotación de compleja lectura. 
Notación aquitana (1 mm) sobre pauta seca. Indica custos.

Bibl.: Dámaso García Fraile, en VV. AA, Las Edades del Hombre: el Árbol de la Vida, Valladolid, 2003, 84-86.

No 55 Graduale, s. XII ex. / s. XIII in. (Feriæ II-III-IV Majoris Hebdomadæ / Sabbato Paschæ / Dominica Octavæ Paschæ / Dominica II post Pascha)

Tabla 0-B

Bifolio suelto, 334 x $458 \mathrm{~mm}$, escritura tirada, 22 líneas, caja 265 x $165 \mathrm{~mm}$.

Escritura gótica de similar módulo. Iniciales azules y verdes con filigrana roja y azul respectivamente. Mayúsculas rojas y azules con filigrana azul y roja; varias mayúsculas negras, algunas embellecidas con filigrana. En el fol. 1r se observan las siguientes anotaciones: «Cartas de venta del prado de Nava el roble que es en el término de Colmenar del Arroyo» en el margen superior; «1558» en el lateral derecho; a continuación de ésta «Vinculado Prado del Roble.» y «Esta aqui la posesion que tomo Francisco de Varros»; más abajo se aprecian diversas anotaciones de compleja lectura. En el margen superior del fol. $2 \mathrm{r}$ se lee: «La dozeava parte de gastos menores es MMMMCCCD maravedíes». Varias anotaciones ilegibles en el borde inferior del fol. $2 \mathrm{v}$.

Notación aquitana (1'5 mm) sobre pauta roja. Indica custos.

Bibl.: Dámaso García Fraile, en VV. AA, Las Edades del Hombre: el Árbol de la Vida, Valladolid, 2003, 84-86 y 419-421.

$\mathbf{N}^{0} 56$ Missale, s. XIII med. (De Trinitate / Dominica I Adventus)

IV-59/1

Bifolio suelto, 330 x $468 \mathrm{~mm}, 2$ columnas, 24-25 líneas, caja 250 x $195 \mathrm{~mm}$.

Escritura gótica a dos módulos, el menor empleado en el texto musical. Dos iniciales grandes en el fol. $2 r$ rellenas con filigrana roja, una es de color azul y la otra alterna los colores azul y rojo; la primera presenta un marco en colores azul, rojo y amarillo; iniciales azules y rojas embellecidas con filigrana roja y azul. Mayúsculas sencillas en colores rojo o negro. Se advierten varias anotaciones: dos en el fol. $2 \mathrm{r}$ «1530 años» y «Apeos de la hacienda del Colmenar del arroyo ymporta al Hospital y a los que compraron de nuevo al Convento»; y otras dos en el fol. 1v, la primera en el borde superior izquierdo y la segunda en el margen lateral izquierdo zona central, ambas ilegibles.

Notación aquitana (1'5 mm) sobre pauta roja. Indica custos. 
$\mathrm{N}^{0} 57$ Psalterium, s. XIII med.

$\mathbf{N}^{\mathbf{0}}$ 57.1 (Psalmi et Canticum)

IV-59/2

Bifolio suelto, 310 x $422 \mathrm{~mm}$, escritura tirada, 21 líneas, caja $210 \mathrm{x}$ $138 \mathrm{~mm}$.

Escritura gótica a dos módulos, el menor empleado en el texto musical. Iniciales azules y rojas adornadas con filigrana roja y azul respectivamente. Mayúsculas rojas sencillas. Se advierten varias anotaciones en el fol. 1r: «Licencia para quel sinador venda. Los bienes de don Pedro de Portugal que quedaron a sus hijos D. Dionis etc. Colmenar y en la misma venta de dichos bienes rayces» en el margen superior, y a continuación «año de 1511».

Notación aquitana (1'5 mm) sobre pauta roja. Indica custos.

$\mathbf{N}^{0} 57.2$ (Psalmi)

IV-59/3

Bifolio suelto, 310 x $435 \mathrm{~mm}$, escritura tirada, 21 líneas, caja 210 x $138 \mathrm{~mm}$.

Escritura gótica a dos módulos, el menor empleado en el texto musical. Iniciales azules y rojas adornadas con filigrana roja y azul respectivamente. Mayúsculas rojas sencillas. Se advierten varias anotaciones en el borde superior del fol. 1r: «(...) Licencia del alcalde para quel sinador venda. Venta. Esto aprovechará al Hospital que posee lo vinculado»; y a continuación «1511». Varias anotaciones ilegibles y ensayos de pluma en el fol. $2 \mathrm{v}$.

Notación aquitana (1’5 mm) sobre pauta roja. Indica custos.

No 58 Graduale, s. XIV ex./ s. XV in. (Pro Defunctis)

$\mathbf{M} / 21$

Dos folios cosidos adosados por su zona externa a las tapas del impreso «Libro primero de la Quarta parte de la Chronica Seraphica. Vida de la gloriosa y bienaventurada virgen Isabel infanta de Francia, monja professa de la orden de Santa Clara» de Fray Damián Cornejo. Sólo se puede leer la cubierta exterior (ff. $1 \mathrm{v}-2 \mathrm{r}$ ), pues la interior está adherida a las tapas del libro. $367 \times 270 \mathrm{~mm}$ cada folio, escritura tirada, 7 renglones, caja $270 \times 215 \mathrm{~mm}$.

Escritura gótica de similar módulo. Iniciales sencillas en colores rojo y negro. Mayúsculas negras sencillas. En el margen inferior del fol. 2r se advierte una anotación ilegible.

Notación cuadrada (4 mm) sobre pentagrama rojo. Indica custos. 
NOTAS PALEOGRÁFICAS Y CODICOLÓGICAS

Una vez agrupados todos los manuscritos por afinidad codicológica y paleográfica, podemos dar noticia de la existencia de 59 códices distintos, los cuales se adscriben a las siguientes tipologías:

- BReviarios: 16

- Siglo XII: $\mathrm{N}^{\circ} 1, \mathrm{~N}^{\circ} 6, \mathrm{~N}^{\circ} 9, \mathrm{~N}^{\circ}$ $10, \mathrm{~N}^{\mathrm{o}} 11, \mathrm{~N}^{\mathrm{o}} 12, \mathrm{~N}^{\mathrm{o}} 13, \mathrm{~N}^{\mathrm{o}} 14 \mathrm{y}$ $\mathrm{N}^{\circ} 54$

- Siglo XIII: N$^{\circ} 19$ y N 24

- Siglo XIV: $\mathrm{N}^{\mathrm{o}} 28$

- Siglo XV: N$^{\circ} 34$, N$^{\circ} 35$, N$^{\circ} 38$ y $\mathrm{N}^{\circ} 46$

- ANTIFonarios DEL OfICIO: 23

- Siglo XIII: $\mathrm{N}^{\mathrm{o}} 15, \mathrm{~N}^{\mathrm{o}} 17, \mathrm{~N}^{\mathrm{o}} 21 \mathrm{y}$ $\mathrm{N}^{\circ} 25$

- Siglo XIV: $\mathrm{N}^{\mathrm{o}} 27, \mathrm{~N}^{\mathrm{o}} 29, \mathrm{~N}^{\mathrm{o}} 30 \mathrm{y}$ $\mathrm{N}^{\circ} 42.2 \mathrm{a}$

- Siglo XV: $\mathrm{N}^{\mathrm{o}} 31, \mathrm{~N}^{\mathrm{o}} 32, \mathrm{~N}^{\mathrm{o}} 33$, $\mathrm{N}^{\circ} 37, \mathrm{~N}^{\mathrm{o}} 39, \mathrm{~N}^{\circ} 40, \mathrm{~N}^{\circ} 42, \mathrm{~N}^{\circ}$ $43, \mathrm{~N}^{\circ} 44, \mathrm{~N}^{\circ} 47, \mathrm{~N}^{\circ} 49, \mathrm{~N}^{\circ} 50$, $\mathrm{N}^{\circ} 51$ y N $\mathrm{N}^{\mathrm{o}} 52$

- Siglo XVI: $\mathrm{N}^{\mathrm{o}} 53$

- Rituales: 2

- Siglo XII: $N^{0} 5$

- Siglo XV: $N^{\circ} 48$
- Consuetudines: 1

- Siglo XIII: $N^{\mathrm{o}} 20$

- Misales: 10

- Siglo XII: $\mathrm{N}^{\circ} 2, \mathrm{~N}^{\circ} 3, \mathrm{~N}^{\circ} 4, \mathrm{~N}^{\circ} 7$ y N 8

- Siglo XIII: $\mathrm{N}^{\mathrm{o}} 16, \mathrm{~N}^{\mathrm{o}} 18, \mathrm{~N}^{\mathrm{o}} 23$, $\mathrm{N}^{\circ} 26$ y No 56

- Graduales: 5

- Siglo XII: N $^{\circ} 55$

- Siglo XIII: $N^{0} 22$

- Siglo XIV: ${ }^{\circ} 58$

- Siglo XV: N $^{\circ} 36$ y No 41

- Himnarios: 1

- Siglo XV: N $^{\circ} 45$

- SALterios: 1

- Siglo XIII: $N^{0} 57$

Como se puede observar, el número de códices destinados al Oficio resulta notablemente superior al de la Misa, circunstancia que no debe extrañar si se tiene en cuenta que este primer ámbito implicaba un mayor número de horas a lo largo de la jornada y era el más rico en expresiones textuales y musicales. Rodríguez Suso esgrime también que este desequilibrio radica en la mayor simplicidad de los cantos del Oficio, circunstancia que estimularía su composición, 
y a la participación más colectiva del clero en su rezo, hecho que provocaría una mayor demanda de sus códices. ${ }^{14}$

La lectura de la anterior estadística revela además que los códices más necesarios tras la restauración de la sede episcopal segoviana fueron los de naturaleza plenaria, de ahí la mayor preponderancia de breviarios y misales durante los siglos XII y XIII. Una vez consolidada la expresión litúrgica local, se detecta una mayor presencia de antifonarios y graduales; hecho constatable sobre todo a partir del siglo XIV. Parece, pues, que desde esa centuria hubo una mayor preocupación hacia el servicio coral. Por otra parte, ninguno de los fragmentos pertenece a tipologías librarias habituales en el marco catedralicio, caso de pontificales, procesionarios o troparios-prosarios. Seguramente, esta ausencia estribe en el mayor lujo y esmero con el que eran confeccionados sus códices, circunstancia que les eximiría de una posterior conversión en guarda..$^{15}$

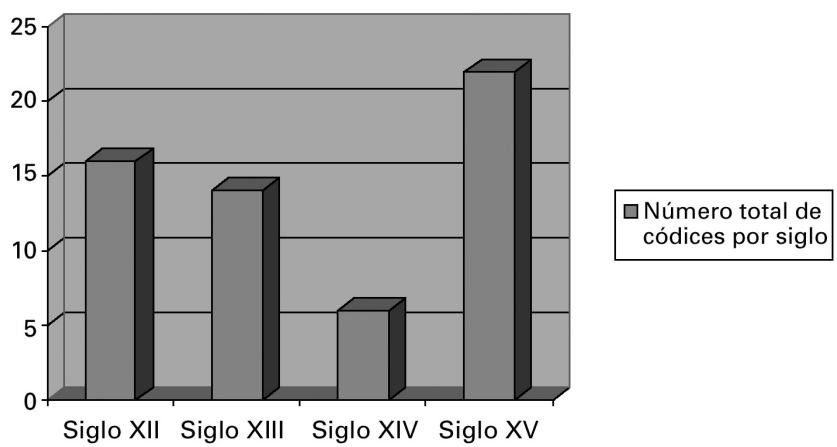

Uno de los factores que pudieron provocar la menor producción de códices litúrgicos durante el siglo XIV, como se observa en la gráfica, pudo ser el alto grado de conservadurismo existente en la liturgia secular durante esa centuria. ${ }^{16}$ Este factor ralentizó probablemente la renovación de los códices preexistentes. Otras posibles explicaciones a este descenso podemos encontrarlas en la menor riqueza codicológica observada en los ejemplares de este periodo, ${ }^{17} \mathrm{y}$ en la compleja situación política, social y cultural que atravesó Castilla a lo largo de este siglo.

${ }^{14}$ C. RodríGuez Suso, La monodia litúrgica ... 749.

15 Ibidem, 754.

16 P. Salmon, L'Office divin au Moyen Âge. Histoire de la formation du brévaire du IXe au XVIe siècle, Lex Orandi 43, París, 1967, 122-123.

${ }^{17}$ H. ANGLés, La Música a Catalunya fins al Segle XIII, Barcelona, 1935, 129.

Hispania Sacra, LXII

126, julio-diciembre 2010, 407-455, ISSN: 0018-215-X 
Del examen de los diferentes pergaminos, puede inferirse que los códices reutilizados como guarda fueron los de confección menos cuidada, es decir, aquéllos de uso común en el clero medio y bajo. La ausencia de elementos decorativos de riqueza como orlas o iniciales historiadas, e incluso la tosca confección de algunas letras capitales, caso de los mss. $\mathrm{N}^{\mathrm{o}} 25.11$ [fol. v] o $\mathrm{N}^{\mathrm{o}} 38$ [fol. r], lo corroboran.

Respecto a las tintas empleadas, se aprecia un mayor uso de los colores negro, rojo y azul, con aparición excepcional de otras tonalidades como violeta, verde o amarillo. Por lo general, las letras capitales suelen ir alternando en su color -comúnmente azul y rojo- para facilitar la localización de las distintas secciones dentro del códice. Esto no siempre ocurre, caso del ms. $\mathrm{N}^{\mathrm{o}} 3.3$, donde las iniciales en rojo dominan de forma abrumadora. Igualmente, percibimos cómo el componente férrico de algunas tintas ha corroído varios pergaminos, como sucede en los mss. $\mathrm{N}^{\circ} 29$ y $\mathrm{N}^{\mathrm{o}} 30$, seguramente a causa de la finura del material utilizado en ambas muestras. Por otra parte, la gama de calidades en los pergaminos resulta bastante desigual, tendiendo por lo común hacia un menor grosor y una progresiva blancura de su superficie con el transcurso del tiempo. No obstante, el deterioro y la suciedad que exteriorizan algunos ítems impiden a veces apreciar esta evolución.

No hemos hallado en los fragmentos ningún testimonio en letra visigótica. La abolición de esta variedad escrituraria en el Concilio de León en 1090, fecha casi coincidente con el inicio de la repoblación en Segovia, parece explicar esta laguna. Ni siquiera el hecho de que se continuara empleando en Castilla aproximadamente hasta $1134,{ }^{18}$ debido a la resistencia suscitada por una parte del clero y al consiguiente proceso de asimilación de la nueva variedad carolina, parece haber dejado huella en estas tierras. A pesar de ello, no descartamos que la comunidad mozárabe presuntamente establecida en la región antes de ser repoblada ${ }^{19}$ poseyera algunos códices en esta letra, si bien en número poco importante dada la situación de marginalidad y despoblamiento que sufrió el territorio segoviano durante la Alta Edad Media.

Ninguna de las fuentes estudiadas, a excepción del ms. $\mathrm{N}^{\circ} 1$, es anterior a mediados del siglo XII. Teniendo en cuenta la necesidad de satisfacer la deman-

18 J. STIEnNon, Paléographie du Moyen Age, París, 1973, 101-102.

${ }^{19}$ La permanencia de núcleos mozárabes en Segovia antes de su repoblación parece haber sido demostrada gracias a estudios toponímicos. De su lectura se desprende que al menos 15 nombres de asentamientos, sobre un total de 195, situados dentro del arcedianato de Segovia a mediados del siglo XIII eran anteriores a dicha repoblación; Ángel BARRIOS GARCÍA, «Despoblación y repoblación del territorio medieval segoviano», Segovia 1088-1988, Segovia, 1991, 23. Esta permanencia de grupos mozárabes durante la Alta Edad Media explica la dedicación de algunos templos segovianos a advocaciones como San Gudumián, San Cebrián o San Briz; J. A. Ruiz Hernando, Historia del Urbanismo en la ciudad de Segovia del siglo XII al XIX, tomo 1, Segovia, 1982, 23. 
da de culto en fechas anteriores, quizás uno de los factores que explican la ausencia de testimonios tempranos estribe en que empleaban letra visigótica aun recogiendo ya rito romano, ${ }^{20}$ la cual con el paso del tiempo resultó ilegible y por eso se abandonó. ${ }^{21}$ Sin duda, el códice $\mathrm{N}^{0} 1$ constituye una de las fuentes más relevantes del catálogo por su antigüedad y porque está redactado íntegramente en letra carolina, variedad escrituraria de escaso arraigo en Castilla. El resto de muestras fechadas en el siglo XII evidencian ya rasgos góticos.

Sorprende, asimismo, el escaso número de enmiendas efectuadas sobre el texto cuando hay errores en la escritura. Tal es el caso, por ejemplo, de la doxología del himno Deus tuorum militum en el breviario $\mathrm{N}^{\circ} 14.1$ [fol. 2r], donde está tachada la expresión «cum spiritu paraclito» por resultar innecesaria, pues la invocación al Espíritu Santo ya figura en la línea superior. Esta falta de revisión del texto induce a pensar que tales errores no eran percibidos como graves por parte del clero, o lo que es peor, ni siquiera eran advertidos, posiblemente a causa de una deficiente formación. ${ }^{22}$ Tampoco los amanuenses parecen salir mejor parados: esta falta de revisión revela que carecían de la preparación, tanto intelectual como cultural, para darse cuenta de sus propios errores.

Pasando a casos más particulares, estimamos que los códices del Archivo capitular B-400 y B-441 debieron pertenecer al obispo segoviano Juan Arias Dávila, aunque sólo figure su ex-libris en el primero de ellos. Varias razones sustentan tal hipótesis. En primer lugar, ambos códices pertenecen a la misma obra: el Liber decretalium del canonista germano Nicolaus de Tudeschis (13861445). Representan respectivamente el volumen I y III de la colección. Además, ambos usan pergaminos procedentes del mismo breviario como hoja de guarda [mss. $\mathrm{N}^{\circ} 14.1$ y N $\mathrm{N}^{\mathrm{o}} 14.2$ ]. Incluso, estos fragmentos remiten a la misma celebración litúrgica: maitines del Común de Apóstoles.

20 Tres códices procedentes del monasterio de Santo Domingo de Silos, actualmente conservados en la British Library de Londres, reúnen estas características: mss. Add. 30.848 (breviario neumado; siglo XI), Add. 30.849 (breviario neumado en sus páginas finales; siglos XI-XII) y Add. 30.850 (antifonario enteramente neumado; siglo XI). Puede consultarse una breve descripción de estos manuscritos en Walter M. WhitehiLl, «The Manuscripts of Santo Domingo de Silos», Homenaje a Fray Justo Pérez de Urbel, OSB, vol. I, Silos, 1976, 288-290. La edición facsímil del antifonario ha sido preparada por I. FERnÁndez de la Cuesta, Antiphonale Silense. British Library Mss. Add. 30.850, Madrid, 1985.

${ }^{21}$ J. JANINI y R. GonZÁlveZ, Catálogo de los manuscritos litúrgicos de la catedral de Toledo, Toledo, 1977, 33 .

22 A pesar de la pobreza de datos existentes acerca de la formación del bajo clero a lo largo de la Baja Edad Media, de la lectura de numerosos concilios y sínodos de la época se constata que este fue un tema que suscitó preocupación entre la jerarquía eclesiástica. Diferentes esfuerzos encaminados a promover su adecuada instrucción no llagaron a fructificar a causa de su escasa preparación intelectual; Ana Arranz GuZMÁn, «La cultura en el Bajo Clero: una primera aproximación» Anuario de Estudios Medievales 21 (1991) 601.

Hispania Sacra, LXII

126, julio-diciembre 2010, 407-455, ISSN: 0018-215-X 


\section{SISTEMAS DE NOTACIÓN Y REPERTORIO MUSICAL}

La evolución gráfica de los sistemas de escritura musical plasmada en los fragmentos entra dentro de los parámetros acostumbrados. En primer lugar, se aprecia que los manuscritos más antiguos emplean neumas aquitanos, lo cual no resulta extraño, pues fue el soporte musical utilizado por Cluny para introducir el rito romano en la Península Ibérica entre finales del siglo XI y principios del XII. ${ }^{23}$ Se detecta, igualmente, cómo, a partir del siglo XIII, este sistema de escritura musical va evolucionando, experimentando sus neumas un aumento de grosor y una tendencia hacia formas cuadradas, lo cual, a la postre, supondrá el triunfo de la notación cuadrada. A partir del siglo XIV, todas las muestras emplean este tipo de variedad notacional inserto siempre dentro de pentagrama. La ausencia del tetragrama en los fragmentos parece revelarnos que no fue un soporte popular por tierras hispanas, hecho ya constatado por Burón Castro y Rodríguez Suso. ${ }^{24}$

La escasa presencia de notación mensural dentro del fondo catalogado, únicamente el himno Tristes erant apostoli $\left[\mathrm{N}^{\mathrm{o}} 32\right.$, fol. $\left.2 \mathrm{v}\right]$, conduce a pensar que no fue una variedad de escritura musical de raigambre en la Península durante la Baja Edad Media. ${ }^{25}$ No obstante, para afianzar esta hipótesis sería conveniente realizar más estudios en torno a la mensuración de la monodia litúrgica, tema aún poco investigado en nuestro país. ${ }^{26}$ Como hecho curioso se puede calificar la adición de neumas aquitanos en el fragmento de Consueta $\mathrm{N}^{\mathrm{0}} 20$, tipología libraria que no suele incorporar notación musical. Tal vez este añadido fue efectuado con objeto de evitar equívocos con piezas homónimas y facilitar la identificación de los cantos. Observamos, igualmente, la ausencia de notación musical en algunos manuscritos con espacio reservado para tal fin, bien en su integridad, caso del breviario $\mathrm{N}^{\circ} 28$, o bien sólo de forma parcial, como sucede en el antifonario $\mathrm{N}^{\circ} 32$. Seguramente quedaron inacabados por no alcanzar las cotas de perfección formal y estética requeridas.

\footnotetext{
${ }^{23}$ Ismael FERNÁNDEZ DE LA CUESTA, «La irrupción del canto gregoriano en España. Bases para un replanteamiento» Revista de Musicología VIII-1 (1985) 247.

24 Taurino Burón CASTRO, «Aportación de fuentes para el estudio del canto llano. Fragmentos musicales del Archivo Histórico Provincial de León», A. GALINDo GARCía (ed.), La Música en la Iglesia de ayer a hoy, Salamanca, 1992, 297; C. RodRÍGUEZ Suso, La monodia litúrgica... 538.

25 Ibidem, 539-540.

${ }^{26}$ La práctica mensural en los himnos ha sido estudiada por Màrius BERNARDó, «Sobre el origen y la procedencia de la tradición himnódica hispánica a fines de la Edad Media» Revista de Musicología 16 (1992) 2335-2353; «The Hymns of the Intonarium Toletanum (1515): Some Peculiarities», Cantus Planus, Hungarian Academy of Sciences, 1995, 367-396; «Adaptación y cambio en repertorios de himnos durante los siglos XV y XVI: algunas observaciones sobre la práctica del canto mensural en fuentes ibéricas», en M. GozZI y F. LUISI (eds.), Il canto fratto: l'altro gregoriano, Roma, 2005, 239279.
} 
Algunas piezas del Oficio recogidas en los fragmentos no han podido ser localizadas hasta la fecha en ninguna otra fuente litúrgica medieval, caso de las antífonas Hoc est opus dei $\left[\mathrm{N}^{\circ} 25.14\right.$, fol. v], Sana me domine quoniam $\left[\mathrm{N}^{\circ} 5\right.$, fol. carne] o Susceptor meus domine gloria mea [ $\mathrm{N}^{\circ} 14.1$, fol. 2r]. Sería necesario ampliar más el radio de investigación antes de poder considerarlas como unica. Asimismo, algunos cantos de la Misa no están recogidos en el Antiphonale Missarum Sextuplex (AMS), ${ }^{27}$ en concreto los aleluyas Erat lucerna ardens $\left[\mathrm{N}^{\circ} 7\right.$, fol. $\left.1 \mathrm{v}\right]$, Levita Laurentius bonum opus $\left[\mathrm{N}^{\circ} 18\right.$, fol. $\left.\mathrm{v}\right]$, Angelus domini descendit $\left[\mathrm{N}^{\circ} 22.2\right.$, fol. v], Sanctissime apostole Jacobe y $O$ patrone sanctissime [ $\mathrm{N}^{\circ} 36$, fol. r], Post dies octo $\left[\mathrm{N}^{\circ} 55\right.$, fol. 2r] y Hosanna filio David $\left[\mathrm{N}^{\circ} 56\right.$, fol. 2v], el gradual Spiritus sanctus super veniet $\left[\mathrm{N}^{\mathrm{o}} 23\right.$, fol. v] y el tracto Ave Maria $\left[\mathrm{N}^{\circ} 23\right.$, fol. v]. Todos ellos, a excepción del gradual, han sido localizados en el misal segoviano impreso en $1500 .{ }^{28}$ Incluso, el aleluya Sanctissime apostole Jacobe podemos divisarlo en el Misal manuscrito del obispo Juan Arias del Villar de finales del siglo XV. ${ }^{29}$ De toda esta relación de piezas sólo subsisten en el Graduale Triplex (GT) los aleluyas Levita Laurentius bonum opus, Angelus domini descendit y Post dies octo. ${ }^{30}$ Este considerable número de aleluyas ausentes en el AMS y en el GT responde a un auge de composición de sus versículos durante el Medioevo, sobre todo entre los siglos IX y XII, ${ }^{31}$ muchos de ellos luego desestimados tras el Concilio de Trento.

Examinando ya casos particulares, constatamos la frecuente aparición de repertorio de Santiago Apóstol. En concreto, son cuatro los fragmentos que contienen monodia para su festividad: mss. $\mathrm{N}^{\circ} 20, \mathrm{~N}^{\circ} 25.1, \mathrm{~N}^{\circ} 36$ y $\mathrm{N}^{\circ} 39.1$. El notable arraigo peninsular hacia esta advocación, unido a la ausencia de este repertorio en AMS, Corpus Antiphonalium Officii (CAO) ${ }^{32}$ y CANTUS CAmpli- $^{33}$ ca cuanto menos que los fragmentos sean hispanos.

27 R. J. Hesbert, Antiphonale Missarum Sextuplex, Roma, reimp. 1985.

28 A. C. Sg., A-70: Erat lucerna ardens, fol. 209r; Levita Laurentius bonum, fol. 225r; Angelus domini descendit, fol. 93v; Sanctissime apostole Jacobe y O patrone sanctissime, fol. 218r; Post dies octo, fol. 98r; Hosanna filio David, fol. 1r; y el tracto Ave Maria, fol. 196r. El texto del gradual Spiritus sanctus super veniet figura como versículo del citado tracto. Acerca de este misal consúltese $\mathrm{n}^{\circ} 324$ de la relación de incunables en C. VALVERde DEL BARRIO, Catálogo de Incunables... 197-198; y n 60 en A. OdRIOZOLA, Catálogo de libros litúrgicos españoles y portugueses, impresos en los siglos XV y XVI, Pontevedra, 1996, 125.

${ }^{29}$ A. C. Sg., Museo 15, sin foliar.

${ }^{30}$ Graduale Triplex, Solesmes, 1979, 588, 201 y 217 respectivamente.

31 J. C. Asensio, El canto gregoriano. Historia, liturgia, formas..., Madrid, 2003, 419. Puede consultarse la melodía y un comentario crítico de todos estos aleluyas, exceptuando los de Santiago Apóstol, en K. Schlager (ed.), Monumenta Monodica Medii Aevi, vols. VII-VIII, Kassel [etc.], 1968 y 1987.

32 R. J. Hesbert, Corpus Antiphonalium Officii, 6 vols., Roma, 1963-1979.

${ }_{33}$ Proyecto de la Universidad Católica de América (Ottawa) encaminado al estudio y catalogación de fuentes litúrgicas medievales. Cfr. http://publish.uwo.ca/ cantus/mssindex.html.

Hispania Sacra, LXII

126, julio-diciembre 2010, 407-455, ISSN: 0018-215-X 
Advertimos la presencia de repertorio no considerado tradicionalmente como gregoriano por su fecha de composición más tardía, pero que depende en muchos casos de él y puede tener incluso su contexto interpretativo dentro de la liturgia. Nos referimos a tropos, secuencias, prosas o cantos votivos en honor a la virgen María o a algún santo. En concreto, hemos encontrado en los fragmentos la prosa de Epifanía Factum est autem [ $\mathrm{N}^{\circ} 15$, fol. v], la secuencia Laude jucunda $\left[\mathrm{N}^{\mathrm{o}} 20\right.$, fol. $\left.1 \mathrm{v}\right]$ y el tropo de «benedicamus» Verbum patris hodie processit [ $\mathrm{N}^{\circ} 35$, fol. v]. Dos muestras ilustrativas de la devoción mariana son el himno Te matrem dei laudamus $\left[\mathrm{N}^{\circ} 40\right], 34$ con texto inspirado en el conocido himno Te deum laudamus, y la popular antífona Salve regina $\left[\mathrm{N}^{\circ} 20\right.$, fol. 2r; $\mathrm{N}^{\mathrm{o}} 39.1$, cubierta interior]..$^{35}$

Asimismo, hemos hallado entre los fragmentos varias antífonas procesionales de escasa difusión: Spiritus sanctus hodie atherea [ $\mathrm{N}^{\circ} 3.3$, fol. 2v], Missus est angelus Gabriel $\left[\mathrm{N}^{\mathrm{o}} 56\right.$, fol. 2r] y Vigilate omnes quia dies domini $\left[\mathrm{N}^{\mathrm{o}} 56\right.$, fol. 2r]. La primera de ellas ha sido identificada por Chevalier como secuencia ${ }^{36}$ no obstante optamos por la anterior denominación porque su interpretación antecede al introito de la Misa. Por su parte, Missus est angelus Gabriel es la única de las tres que está incluida en el CAO, si bien sólo en el antifonario de la abadía de Saint-Maur-les-Fossés de observancia cluniacense. ${ }^{37}$ Finalmente, Vigilate omnes quia dies domini sólo ha podido ser localizada en el listado de antífonas procedente de fuentes italianas compilado por el profesor Giacomo Baroffio. ${ }^{38}$

Por otra parte, algunos de los ofertorios de la Misa presentan varios versículos, caso de Emitte spiritum tuum et creabuntur $\left[\mathrm{N}^{\circ} 3.3\right.$, fol. $\left.2 \mathrm{v}\right]$ o Expectans expectavi dominum $\left[\mathrm{N}^{\mathrm{o}} 8\right.$, fol. $2 \mathrm{r}$ ], circunstancia que manifiesta la antigüedad de las fuentes. ${ }^{39}$

\footnotetext{
34 Puede consultarse el texto íntegro de este himno en J. L. VillanUEVA, Viage literario á las iglesias de España, tomo I, Madrid, 1803, 108-109. Otra fuente hispana que contiene este canto es el ms. Ripoll 116 [fol. 101v], fechado en el siglo XII; I. FERnÁndeZ DE LA CuESTA, Manuscritos y Fuentes Musicales en España. Edad Media, Madrid, 1980, 342. Acerca de esta composición véase Bonnie J. Blackburn, «Te Matrem Dei Laudamus. A Study in the Musical Veneration of Mary» The Musical Quarterly 53/1 (1967) 53-76.

35 Varias referencias documentales fechadas en el siglo XVI atestiguan la interpretación de la Salve regina en la catedral de Segovia; véanse docs. nos 135 y 144 en J. LóPEZ-CALO, Documentario musical de la catedral de Segovia, vol. I. Actas Capitulares, Santiago de Compostela, 1990, 10-11.

${ }^{36}$ RH 33640; U. CHEVALIER, Repertorium Hymnologicum, 6 vols., Louvain, 1892-1920.

${ }^{37}$ CAO III, 338.

${ }^{38} \mathrm{Cfr}$. http://musicologia.unipv.it/baroffio/repertori.html.

${ }^{39}$ D. HILEY, Western Plainchant, Oxford, 1993, 121.
} 


\section{Procedencia DE LOS MANUSCRITOS}

Deducir la procedencia de los manuscritos ha representado uno de los objetivos prioritarios en este estudio. Sin embargo, la escasa información suministrada por los fragmentos y la práctica inexistencia de elementos individualizadores en los mismos han dificultado esta verificación. De hecho, los códices litúrgicos constituyen la producción más serializada de la escritura manual a lo largo del Medioevo. ${ }^{40}$ Conviene puntualizar que hemos asumido la diferenciación establecida por la codicología entre origen, entendido como centro productor del códice, y procedencia, institución o persona que lo poseyó, ya que no siempre resultan coincidentes.$^{41} \mathrm{~A}$ este segundo contexto es al que vamos a referirnos en este apartado ya que la estructuración y contenido de un códice respondían al criterio del poseedor.

El hecho de que los manuscritos se hayan conservado en archivos segovianos no implica forzosamente que respondan al culto allí celebrado. En efecto, el comercio de pergamino durante los siglos XVI y XVII provocó la dispersión de numerosas fuentes. Además, debemos tener en cuenta que el fondo librario en una biblioteca de cierta antigüedad, caso de los archivos estudiados, no suele ser homogéneo. Mas bien, es resultado de la acumulación de otros fondos menores de procedencia diversa.

El tipo de notación empleado en los fragmentos tampoco resulta ilustrativo en este sentido. Huglo apunta que la notación aquitana se muestra inadecuada para determinar si el manuscrito es de origen francés o hispano ya que las diferencias halladas a ambos lados de los Pirineos en cuanto al trazo y distribución de los neumas resultan mínimas. ${ }^{42}$ En el caso de la notación cuadrada, el otro sistema de escritura musical predominante en los manuscritos, la verificación de la procedencia resulta aún más problemática pues su plasmación no obedece a modelos locales ${ }^{43}$ y su difusión está asociada a la expansión de las órdenes mendicantes, sumamente móviles por naturaleza. ${ }^{4}$

\footnotetext{
${ }^{40}$ C. RodríGuez Suso, La monodia litúrgica... 787.

${ }^{41}$ D. HiLey, Western ... 335.

42 Michel Huglo, «La pénétration des manuscrits aquitains en Espagne» Revista de Musicología VIII-1 (1985) 253 y 256.

43 J. C. AsENSIO, El canto gregoriano... 401.

${ }^{44}$ C. RodríGuez Suso, La monodia litúrgica... 791. 


\section{Procedencia de los códices}
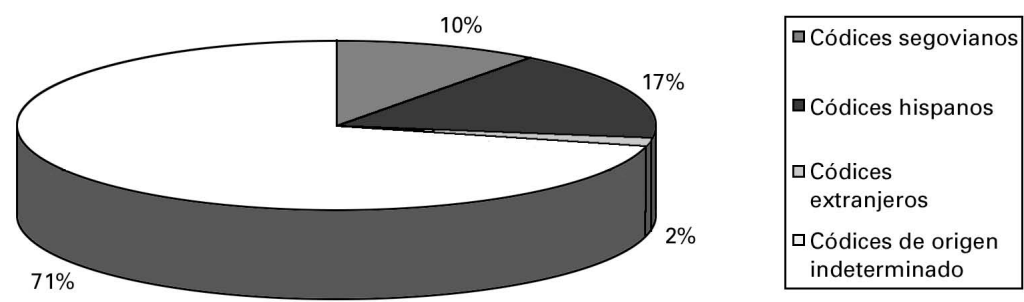

Gracias sobre todo a la comparación sistemática de los fragmentos respecto a los códices litúrgicos segovianos, hemos podido demostrar la procedencia local de 6 manuscritos en donde se insertan un total de 22 fragmentos. En concreto, los mss. $\mathrm{N}^{\mathrm{o}} 15, \mathrm{~N}^{\mathrm{o}} 17, \mathrm{~N}^{\mathrm{o}} 19, \mathrm{~N}^{\mathrm{o}} 20, \mathrm{~N}^{\mathrm{o}} 25$ y $\mathrm{N}^{\mathrm{o}} 46$. Entre ellos, merece la pena resaltar el antifonario $\mathrm{N}^{\mathrm{o}} 25$ por la cantidad de ítems que engloba -16 fragmentos-, $\mathrm{y}$ por su relevancia histórico-cultural, pues da noticia de la existencia de un antifonario medieval en Segovia, aspecto desconocido hasta la fecha. Ninguna de estas muestras pertenece a las Carmelitas descalzas. Ello permite deducir que sus fragmentos provienen de otros espacios eclesiales. Seguramente, éstos recabaron en Segovia tras la fundación de su convento en 1574.

A su vez, 10 códices, a los que pertenecen 20 fragmentos, parecen ser de origen hispano. Nos referimos, en concreto, a los mss. $\mathrm{N}^{\circ} 1, \mathrm{~N}^{\mathrm{o}} 2, \mathrm{~N}^{\mathrm{o}} 3, \mathrm{~N}^{\mathrm{o}} 10, \mathrm{~N}^{\mathrm{o}} 13$, $\mathrm{N}^{\circ} 22, \mathrm{~N}^{\circ} 36, \mathrm{~N}^{\circ} 39, \mathrm{~N}^{\circ} 54$ y $\mathrm{N}^{\circ} 56$. El hecho de que reflejen culto hacia ciertos santos de raigambre hispana o que consignen variantes textuales emanadas de códices litúrgicos que sirvieron de base para la codificación de numerosas consuetudinis peninsulares, caso del antifonario aquitano $44.2,45$ ha posibilitado tal asociación.

Sin duda, el breviario $\mathrm{N}^{\circ} 12$, conformado por dos fragmentos que recogen parte del Oficio de los SS. Cornelio y Cipriano, más un extracto de calendario, constituye una de las fuentes más notables del catálogo. Lo primero que llama la atención es la notación mayoritariamente adiastemática empleada en los cantos, la cual podríamos calificar como una evolución de Laon. Conocemos que esta tipología de escritura musical se circunscribió principalmente a las regiones francesas de Lorena y Champagne, los Países Bajos y algunos puntos aislados de Alemania, Polonia, Bohemia, Hungría, Austria y Lombardía, ${ }^{46}$ y desde

\footnotetext{
${ }^{45}$ Códice conservado en la Biblioteca capitular de Toledo; véase J. JANINI y R. GonZÁlveZ, Catálogo de los manuscritos... 179-180. Acerca de la importancia de este antifonario en la introducción del rito francorromano en la Península consúltese Pedro Romano RocHA, «Influjo de los antifonarios aquitanos en el oficio divino de las Iglesias del noroeste de la Península», Estudios sobre Alfonso VI y la reconquista de Toledo, Toledo, 1990, 27-45.

${ }^{46} \mathrm{H}$. Beguermont, La première écriture musicale du monde occidental, Bourg-la-Reine (France), 2003, 129.
} 
luego no fue introducida en la Península Ibérica. Este es un elemento decisivo para determinar que el manuscrito no es hispano. Otras pruebas que refuerzan esta hipótesis son la ausencia de la festividad de los mártires Cornelio y Cipriano en los calendarios medievales segovianos, la peculiar caligrafía adoptada en las iniciales y el mayor grosor y rigidez de su pergamino respecto al resto de manuscritos. El fragmento de calendario resulta determinante a la hora de averiguar la procedencia: la inclusión de conmemoraciones como San Wandrille, Santa Amalberge, San Goaris o Santa Landrade revela que el centro para el cual fue compilado se asentaba en un área comprendida entre el Rhin y el Sena, probablemente en torno a los actuales Países Bajos. De hecho, sólo hemos podido detectar el repertorio de los SS. Cornelio y Cipriano en tres fuentes de esta región indexadas por CANTUS. En concreto, los antifonarios de Aachen D-AAm G 20 (ca. 1318), Cambrai F-CA 38 (ca. 1230-1250) y Utrecht NL-Uu 406 (siglo XII con adiciones del XIII, XIV y XV).

En este breviario $\mathrm{N}^{\circ} 12$ podemos además divisar un extracto del responsorio $O$ crux admirabilis añadido con posteridad, en el cual se puede apreciar el uso de esta notación emanada de Laon ahora adaptada a un sistema de pautas. Finalmente, el códice en donde se localizan estos fragmentos (A. C. Sg., B-364), datado en 1426, debió ser encuadernado también en los Países Bajos por el marcado arcaísmo tanto formal como material evidenciado en sus tapas. ${ }^{47}$ Posteriormente fue adquirido por el obispo Juan Arias Dávila en circunstancias aún desconocidas, el cual lo legó a la catedral tras su muerte.

Del resto, 42 códices que engloban un total de 45 fragmentos, no tenemos certeza de su lugar de procedencia. Ello se debe a varios condicionantes, como son la mínima información que suministran los fragmentos posteriores al siglo XIII por el mayor módulo de letra empleado, y la uniformidad que evidencia el repertorio de la Misa durante el Medioevo. Tampoco los ítems adscritos a tipologías codicológicas particulares, como los rituales $\mathrm{N}^{\circ} 5$ y $\mathrm{N}^{\circ} 48$, el himnario $\mathrm{N}^{\circ} 45$ o el salterio $\mathrm{N}^{\circ} 57$, así como los que incluyen repertorio de carácter generalista, caso del prefacio de la Misa [ $\mathrm{N}^{\mathrm{o}} 26$ ] o las fórmulas de benedicamus domino [ $\mathrm{N}^{\mathrm{o}} 51$ ], pueden ser vinculados a centro eclesiástico alguno por su mero contenido musical.

Con todo, no descartamos que la inmensa mayoría de los fragmentos, cuando no todos, sean al menos hispanos, e incluso bastantes de ellos segovianos. A pesar de la mencionada dispersión de manuscritos fruto del comercio del pergamino, resulta bastante probable que los talleres de encuadernación a la hora de confeccionar guardas se hicieran con remanente procedente de la zona donde estaban asentados. No nos parece además inverosímil que los mismos eclesiásticos aprendiesen

${ }^{47}$ El arcaísmo es un rasgo asociado a las encuadernaciones flamencas y alemanas. Véase Juan Antonio YEVES ANDRÉS, «Encuadernaciones en las colecciones eclesiásticas: técnicas, tipologías y estilos» Memoria Ecclesia 33 (2009) 329.

Hispania Sacra, LXII

126, julio-diciembre 2010, 407-455, ISSN: 0018-215-X 
a encuadernar sus legajos documentales en el estilo denominado «a la holandesa», variedad puramente funcional en la que el pergamino actúa de cubierta al escrito que se quiere preservar, ${ }^{48}$ pues no resulta una técnica compleja y supondría un ahoro bastante considerable. Pruebas de tales prácticas en Segovia nos han llegado por medio de las actas capitulares. ${ }^{49}$ De todas formas, juzgamos más probable que la Iglesia local cediese pergamino ya en desuso a talleres especializados con objeto de encuadernar sus códices y registros documentales, circunstancia que tampoco enturbiaría la vinculación local de numerosos fragmentos.

\section{LOS FRAGMENTOS Y EL RITO ROMANO EN LA SEGOVIA MEDIEVAL}

Los 23 fragmentos fechados en el siglo XII resultan muy ilustrativos desde el punto de vista litúrgico, porque dan noticia de usos rituales en un periodo en el que numerosas consuetudines peninsulares estaban sin codificar. Aunque no hayamos podido demostrar su filiación con Segovia, es probable que algunos de ellos representen testimonios tempranos de su tradición cultual. Los 22 fragmentos identificados como segovianos, junto al resto de códices litúrgicos conservados en el Archivo capitular, permiten desentrañar las claves fundamentales del culto local. En primer lugar, evidenciamos un fuerte aporte de Cluny, merced a la impronta ejercida por sus primeros obispos, todos oriundos de Francia y familiarizados con su tradición..$^{50}$ Esta influencia viene refrendada por la vinculación que muestran las fuentes locales respecto al antifonario aquitano 44.2, códice concordante en gran medida con su tradición. ${ }^{51}$ Advertimos, sin embargo, rasgos que difieren de Cluny. Ello induce a pensar que hubo otros modelos, e incluso, que hubo una reelaboraron a partir de aquel antifonario con el fin de garantizar la individualidad del modelo ritual.

\footnotetext{
48 D. BANET, Encuadernación en 5 Lecciones, Barcelona, 1978, 6.

49 En concreto, un acuerdo del cabildo en 1505 instaba a tres canónigos a que aprendieran cómo elaborar libros. Véase doc. $\mathrm{n}^{\circ} 71$ en J. LóPEZ-CALO, Documentario musical... 5-6.

50 Nos referimos en concreto a Pedro de Agen (1120-ca.1148) y Juan de Castellmorum (ca.11491153). Acerca de estos prelados consúltese Bonifacio BARTOLOMÉ HERRERO, «Obispos extranjeros al frente de la diócesis de Segovia (1120-1742)» Estudios Segovianos 105 (2005) 25-29. En contra del parecer de algunos autores, estimamos como poco probable que Pedro fuera cluniacense; A. LINAGE CONDE, «La donación de Alfonso VI a Silos del futuro priorato de San Frutos y el problema de la despoblación» Anuario de Historia del Derecho Español 41 (1971) 990; L. M. VILlar García, La Extremadura Castellano-Leonesa... 210; J. GARCÍA HERnANDO, «Apuntes para la historia de la diócesis de Segovia»Estudios Segovianos 64 (1970) 120; Idem, «Segovia, Diócesis de», en Q. AldEA VAQUERO, T. Marín Martínez y J. Vives Gatell (dirs.), Diccionario de Historia Eclesiástica de España, vol. IV, Madrid, 2393; J. PÉrez VillanueVA, «Repoblación de Segovia restauración de su obispado algunas cuestiones críticas», Segovia 1088-1988, Segovia, 1991, 189.

51 J. P. RuBIo SADIA, Las Órdenes religiosas y la introducción del Rito Romano en la Iglesia de Toledo, Toledo, 2004, 176.
} 
No hemos podido cuantificar el posible aporte en materia litúrgica recibido desde centros monásticos como Santo Domingo de Silos, Valvanera o San Millán de la Cogolla, relacionados históricamente con Segovia. El elemento más sólido para probar una conexión entre la liturgia segoviana y Santo Domingo de Silos, con presencia en la región a través del priorato de San Frutos del Duratón, ha sido la inclusión de la epístola farcida Laudes deo dicam ${ }^{52}$, visible en el gradual $\mathrm{N}^{\circ} 22$, en el misal y tropario-prosario Salamanca ms. 2637, fuente del siglo XII señalada por algunos expertos como proveniente de la abadía burgalesa. ${ }^{53}$ De todas formas, esta vinculación no es segura porque no se ha podido demostrar la pertenencia a Segovia del citado gradual. Respecto a Valvanera y San Millán de la Cogolla sabemos de su colaboración en la repoblación de Segovia entre finales del siglo XI y principios del XII, ${ }^{54}$ pero falta aún un estudio que compare sus fuentes litúrgicas con las segovianas.

Resulta también bastante probable que la Iglesia local asimilase elementos provenientes de otras diócesis peninsulares. La prueba más decisiva ha sido la presencia del aleluya Fulgebunt justi $\left[\mathrm{N}^{\mathrm{o}} 25.3\right.$, fol. r] dentro de las segundas vísperas de Todos los Santos. La interpretación de aleluyas de la Misa durante esta hora litúrgica en las celebraciones de mayor rango es un tema aún pendiente de estudio. No advertidos en Toledo, cabeza de la provincia eclesiástica a la que pertenecía Segovia, hasta finales del siglo XV, 55 figuran en fuentes más antiguas del noroeste peninsular. ${ }^{56}$ Ello induce a pensar que pudo ser un elemento que Segovia importó de la metrópoli de Compostela, tal vez a través de la vecina diócesis de Avila.

La ausencia de códices litúrgicos en Segovia en el siglo XII denota que fue un período de transición y configuración en materia ritual. Probablemente, la consuetudo romano-diocesana no fue codificada hasta finales del siglo XII o principios del XIII, pues los primeros códices conservados datan de esta época.

52 C. Blume (ed.), Tropen des Missale im Mittelalter, Analecta Monodica Medii Aevi 49, Frankfurt am Main, 1961, 169.

53 Olim Madrid, Palacio Real, Sign. 492, ant. II.D.3, fol. 11v. Puede consultarse la historia y descripción codicológica de este manuscrito en E. CASTRO, Tropos y troparios hispánicos, Santiago de Compostela, 1991, 167-173 y 292-295. Hasta el momento sólo hemos podido localizar este canto dentro de la geografía peninsular en Toledo (B. C., ms. 35.18, fol. 11v), Valencia (A. C., ms. 89, fol. 25r y ms. 100, fol. 8r), León (A. C., ms. 23, fol. 1r) y en la Biblioteca de la Real Academia de la Historia de Madrid (Aemil 55, fol. 125v).

${ }^{54}$ M. Barrio Gozalo (et al.), Historia de Segovia, Segovia, 1987, 58.

$55 \mathrm{La}$ primera fuente conservada en el Biblioteca capitular de Toledo que menciona la interpretación de aleluyas en las segundas vísperas es el breviario 33.7, copiado hacia 1475; puede consultarse una descripción de este manuscrito en J. JANINI y R. GonZÁlveZ, Catálogo de los manuscritos... 65-66. En ningún caso este códice especifica el aleluya que debe ejecutarse en cada celebración.

56 Pedro Romano RocHA, «La liturgia de Compostela a fines del siglo XII», O Portico da Gloria e o Arte do seu tempo, La Coruña, 1991, 406.

Hispania Sacra, LXII

126, julio-diciembre 2010, 407-455, ISSN: 0018-215-X 
La comparación del repertorio recogido en distintas fuentes litúrgicas locales fechadas entre los siglos XIII y XVI permite deducir que su tradición cultual se mantuvo bastante estable hasta Trento. Hallamos también en este periodo pequeños cambios, especialmente en el Santoral, que pueden ser calificados como menores. Un ejemplo de ello lo tenemos en el Oficio de la Inmaculada Concepción:

\begin{tabular}{|c|c|c|c|}
\hline$\underline{\mathbf{N}^{0} 19}$ & $\frac{\text { B-272 }}{\text { [fol. 170v] }}$ & $\underline{\text { Bfol. } 115 \mathrm{v}]}$ & $\stackrel{\text { E-37 }}{[\text { fol. } 435 r]}$ \\
\hline $\begin{array}{l}\text { Ad vesperas } \\
\text { A. Gaude mater ecclesia nova }\end{array}$ & $=$ & $=$ & Gloriosæ virginis Mariæ \\
\hline R. Cordis ac vocis jubilo & $=$ & $=$ & - \\
\hline A. Magn. Ave decus virgineum & $=$ & $=$ & Beatissimæ virginis Mariæ \\
\hline $\begin{array}{l}\text { Ad completam } \\
\text { A. Sancta dei genetrix virgo }\end{array}$ & $=$ & $=$ & Conceptio tua dei genetrix \\
\hline A. Nunc Cum jucunditate & $=$ & $=$ & $=$ \\
\hline
\end{tabular}

Fuentes comparadas:

$\mathrm{N}^{\circ}$ 19: Fragmento de breviario (siglo XIII, mediados)

B-272: Breviario (siglo XV, mediados)

B-428: Consuetudinis ecclesiae segobiensis del obispo Juan Arias Dávila (1484)

E-37: Breviario impreso (1527)

Otro oficio, modificado con el tiempo, es el de Santiago Apóstol, tanto en su conmemoración del 25 de julio como en la fiesta de la traslación de sus reliquias (30 de diciembre). Mientras que el breviario B-288 (siglos XIII-XV) incluye sólo unos pocos cantos propios de la primera celebración,,${ }^{57}$ omitiendo la segunda; el breviario B-272 y la Consueta B-428 incorporan ambas festividades de forma íntegra. ${ }^{58}$ Probablemente, la fiesta de la Traslación del apóstol Santiago debió ser introducida en la diócesis segoviana entre finales del siglo XIII y principios del XIV, pues ya el fragmento de antifonario $\mathrm{N}^{\circ} 25.1$, fechado alrededor de esta época, la incluye.

Finalmente, la irrupción de la imprenta a finales del siglo XV, episodios bélicos como la Guerra de las Comunidades en 1520, la aludida uniformización litúrgica decretada en Trento y la mentalidad hostil hacia lo gótico auspiciada por el Humanismo condujeron al arrinconamiento y destrucción de buena parte de los códices litúrgicos locales. Al quedar obsoletos para el culto y no existir una mentalidad historicista que procurase su conservación, muchos terminaron

${ }^{57}$ A. C. Sg., B-288, ff. 174v-175v.

58 Santiago Apóstol: B-272, ff. 95v-97v del Santoral y B-428, ff. 95v-96r. Traslación de Santiago Apóstol: B-272, ff. 8r-10v del Santoral y B-428, ff. 77v-78r 
sirviendo de guarda a documentos de distinta índole. Con todo, ese nuevo uso ha posibilitado la supervivencia de unos testimonios que seguramente se hubieran perdido bajo otras condiciones.

\section{BALANCE FINAL}

Estos son los aspectos más destacados que se desprenden del estudio de este corpus de fragmentos litúrgico-musicales:

- La asociación de los 89 fragmentos estudiados ha posibilitado dar noticia de 59 códices distintos, en particular antifonarios, breviarios y misales, tipologías imprescindibles para el desarrollo de las distintas celebraciones litúrgicas. Los códices plenarios resultan más numerosos entre los siglos XII y XIII, seguramente por la necesidad de garantizar las necesidades de culto en la diócesis segoviense tras la restauración de 1120 .

- Los pergaminos examinados presentan una calidad de confección mediabaja. En ningún caso pertenecen a tipologías codicológicas asociadas al lujo, caso de pontificales. Ello sugiere que los manuscritos empleados como guarda fueron los de uso común en el clero.

- Los sistemas de notación empleados en los fragmentos reflejan cierto conservadurismo en cuanto a los usos musicales. Puede verificarse sobre todo en dos hechos: el escaso empleo de notación mensural en los cantos, únicamente el mencionado himno Tristes erant apostoli $\left[\mathrm{N}^{\mathrm{o}} 32\right.$, fol. 2v]; y la tardía aparición de la notación cuadrada y el pentagrama en las fuentes locales. La transición hacia formas cuadradas en la escritura musical no se percibe hasta el siglo XIII, sobre todo en su tramo final, mientras que el pentagrama no aparece hasta el siglo XIV.

- La ausencia de algunos cantos del Oficio en repertorios de fuentes litúrgicas como CANTUS o CAO, caso de las antífonas Hoc est opus dei [ $\mathrm{N}^{\circ} 25.14$, fol. v], Sana me domine quoniam [ $\mathrm{N}^{\circ}$ 5, fol. carne] o Susceptor meus domine gloria mea [ $\mathrm{N}^{\circ} 14.1$, fol. 2r], manifiesta su excepcionalidad. Sin embargo, antes de calificar cada uno de estos ítems como unicum sería conveniente revisar un mayor número de fuentes.

- La identificación como segovianos de una cuarta parte de los manuscritos (22 ítems) resulta muy significativo, habida cuenta de las dificultades existentes a la hora de asociar los fragmentos litúrgicos a una Iglesia local. Destaca dentro de este conjunto el antifonario $\mathrm{N}^{\circ} 25$, ejemplar que engloba 16 manuscritos.

- Debemos poner de relieve, a su vez, la huella de Cluny que presenta la liturgia segoviana. Ello se percibe sobre todo en la notable vinculación de las 
fuentes locales respecto a manuscritos de tradición cluniacense como el antifonario aquitano 44.2 y el antifonario de Saint-Maur-les-Fossés.

- Divisamos otros elementos en la liturgia local que parecen testimoniar la convergencia de distintos influjos, bien monásticos o seculares, en la codificación de su costumbre ritual. No nos es posible identificar aún la procedencia de éstos, e incluso, hasta qué punto resultan producto de una importación o responden a una iniciativa consciente que buscara la individualización del esquema cultual.

Finalmente, conviene resaltar el valor de los trabajos en torno a los fragmentos de códices, no sólo por el hecho de dar a conocer documentos inéditos, sino también por los consiguientes beneficios que pueden reportar a la investigación medieval, muchas veces limitada por falta de fuentes. A pesar de no haber abarcado todos los archivos que puedan albergar fragmentos de procedencia local, consideramos que este estudio representa un avance fundamental acerca del rico patrimonio de la liturgia y monodia segovianas, sobre todo por haber incorporado las fuentes provenientes de su catedral, la institución más importante dentro del territorio diocesano. Esta contribución y otras de similares características continúan siendo insuficientes a la hora de reconstruir de forma sistemática la liturgia celebrada en la Península Ibérica durante el Medioevo. El precario estado de conservación que exteriorizan algunas muestras hace, si cabe, más urgente la realización de este tipo de trabajos, pues aún son muchas las instituciones eclesiásticas y civiles diseminadas por nuestra geografía nacional que atesoran ricos fondos codicológicos inéditos. 